\title{
Discerning the Diets of Sweep-Feeding Eurypterids Through Analyses of Mesh-Modified Appendage Armature
}

\author{
Emily Samantha Hughes \\ esh0008@mix.wvu.edu
}

Follow this and additional works at: https://researchrepository.wvu.edu/etd

Part of the Paleobiology Commons, and the Paleontology Commons

\section{Recommended Citation}

Hughes, Emily Samantha, "Discerning the Diets of Sweep-Feeding Eurypterids Through Analyses of MeshModified Appendage Armature" (2019). Graduate Theses, Dissertations, and Problem Reports. 3890.

https://researchrepository.wvu.edu/etd/3890

This Thesis is protected by copyright and/or related rights. It has been brought to you by the The Research Repository @ WVU with permission from the rights-holder(s). You are free to use this Thesis in any way that is permitted by the copyright and related rights legislation that applies to your use. For other uses you must obtain permission from the rights-holder(s) directly, unless additional rights are indicated by a Creative Commons license in the record and/ or on the work itself. This Thesis has been accepted for inclusion in WVU Graduate Theses, Dissertations, and Problem Reports collection by an authorized administrator of The Research Repository @ WVU. For more information, please contact researchrepository@mail.wvu.edu. 
Discerning the Diets of Sweep-Feeding Eurypterids Through Analyses of Mesh-Modified Appendage Armature

Emily Hughes

Thesis submitted

to the Eberly College of Arts and Sciences at West Virginia University

in partial fulfillment of the requirements for the degree of

Master of Science in Geology

\author{
James Lamsdell, Ph.D., Chair \\ Curtis Congreve, Ph.D. \\ Craig Barrett, Ph.D. \\ Department of Geology and Geography
}

Morgantown, West Virginia

2019

Keywords: eurypterids, sweep feeding, prey size, ontogeny, niche shift Copyright 2019 Emily Hughes 


\author{
ABSTRACT \\ Discerning the Diets of Sweep-Feeding Eurypterids \\ Through Analyses of Mesh-Modified Appendage Armature \\ Emily Hughes
}

Eurypterids were a group of aquatic chelicerates that lived throughout most of the Paleozoic. While swimming eurypterids are generally considered to be active predators, the benthic stylonurine eurypterids appear to have had a mode of life similar to modern horseshoe crabs with the exception of two clades, the Stylonuroidea and the Mycteropoidea, both of which independently evolved modifications for sweep-feeding on their anterior appendages. Among extant suspension feeders, it has been shown that there is a linear correlation between the average spacing of feeding structures and prey sizes. This relationship was extrapolated to the sweepfeeding stylonuroid and mycteropoid eurypterids in order to estimate the range of prey sizes that they could capture. The majority of eurypterids are found to have armature spacing within a range of $2.5 \mathrm{~mm}$ to $4.6 \mathrm{~mm}$, which corresponds to a prey size range of $3.6 \mathrm{~mm}$ to $58 \mathrm{~mm}$. This suggests that the armature of the sweep-feeding eurypterids was optimally suited for capturing small macrofauna. Benthic macroinvertebrates such as crustaceans, mollusks, and worm-like organisms would have been manageable prey items.

The mycteropoid Cyrtoctenus was the most specialized genus of sweep-feeders, and its appendage armature consisted of two rows of flexible filaments extending anteriorly from rachises forming comb-like structures. The rachises were associated with moveable spines on the anterior-ventral sides of the podomeres, which would scrape the filaments and eject trapped food particles into the oral region. Cyrtoctenus had the smallest estimated prey size among eurypterids, and its inter-filament spacing suggests its diet consisted of mesoplankton. The 
mycteropoids radiated in the Late Devonian and Carboniferous, and they were one of only two groups of eurypterids that persisted into the late Paleozoic. Their success was likely due to their wide distribution and sweep-feeding mode of life, which allowed them to avoid competition with nektonic predators while capitalizing on the expanding benthos, which was invading freshwater environments in the Devonian and Carboniferous.

It has been proposed that several of the mycteropoid genera are synonyms. In particular, Hibbertopterus may be a juvenile form of Cyrtoctenus in which case the comb-like rachises did not develop until the late stages of ontogeny, and juveniles retained broad blades suited to probing for prey in soft sediment but incapable of capturing small prey out of suspension. In order to evaluate the likelihood of synonymy, the ornamentation of several mycteropoids was compared and found to be largely consistent in Hibbertopterus, Dunsopterus, and Cyrtoctenus. The strong morphological similarities between Hibbertopterus and Dunsopterus in particular warrant their synonymization, and because Dunsopterus is paraphyletic with respect to Cyrtoctenus, all three genera can be synonymized. The overall form and ornamentation of the moveable blades of Hibbertopterus suggests that these blades are the precursors to the moveable fingers of Cyrtoctenus. The comb rachises of Cyrtoctenus are much thinner than the moveable fingers and lack folliculated ornamentation, suggesting that they are not derived from the same moveable blades, but rather from fixed posterior-ventral spines. This ontogenetic niche shift would have resulted in distinct prey sizes between juveniles and adults which would have increased survival rates by reducing intraspecific competition. 


\section{ACKNOWLEDGEMENTS}

Foremost, I would like to thank my advisor, Dr. James Lamsdell, who provided guidance and support throughout the entirety of this project. Without his expertise and assistance, this thesis would not have been possible. Special thanks to the Paleontological Society, which supported this project through the Rodney M. Feldmann grant, and my sincerest gratitude to Dr. Andrew Ross of the National Museum of Scotland and to Mr. Paul Shepherd of the British Geological Survey for facilitating access to specimens. Last but not least, I would like to thank my family for their continued support and encouragement throughout the years. 


\section{TABLE OF CONTENTS}

CHAPTER 1- DISCERNING THE DIETS OF SWEEP-FEEDING EURYPTERIDS ............................. 1

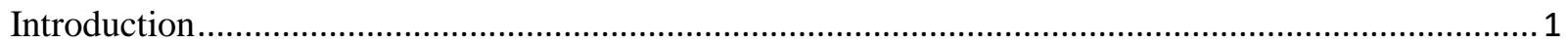

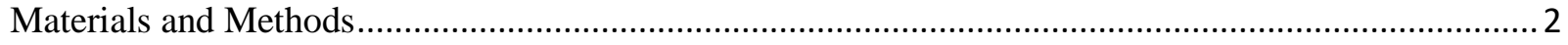

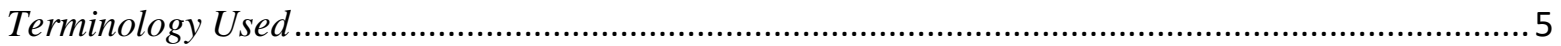

Appendage Morphology and Feeding Strategies of Stylonurine Eurypterids........................................ 5

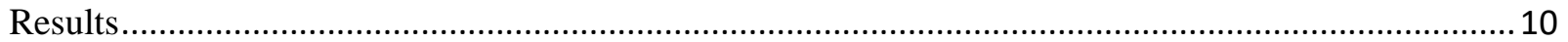

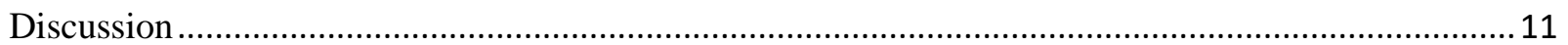

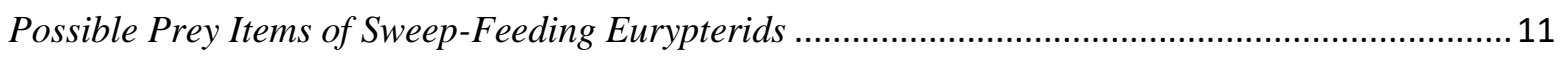

Feeding Strategies of the Stylonurine Eurypterids ....................................................................... 11

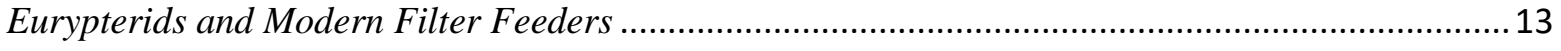

Eurypterids and the Late Devonian Mass Extinction Event …......................................................15

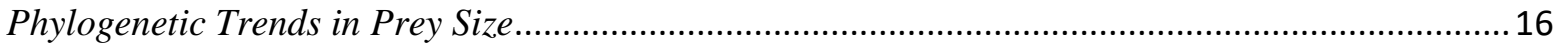

Possible Factors Influencing Survival Rates ...........................................................................

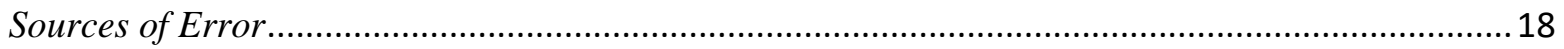

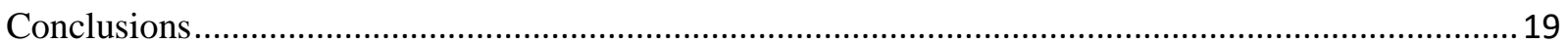

CHAPTER 2- EVALUATING THE POSSIBILITY OF SYNONYMY AMONG HIBBERTOPTERID

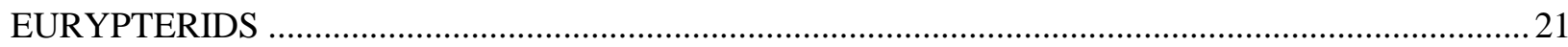

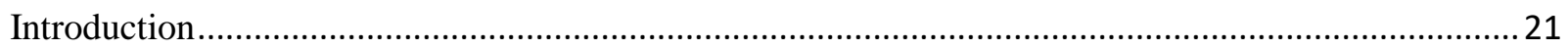

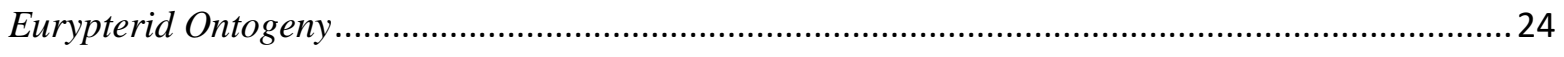

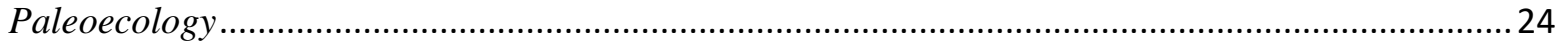

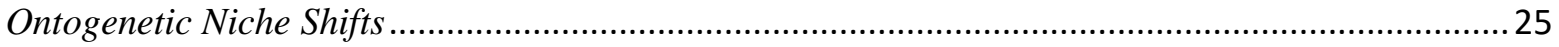

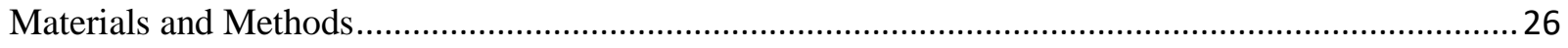

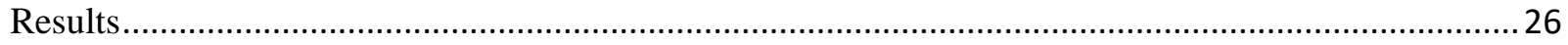

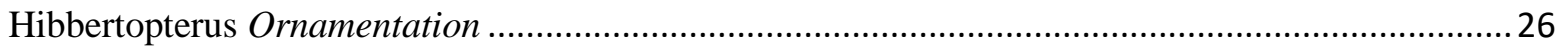

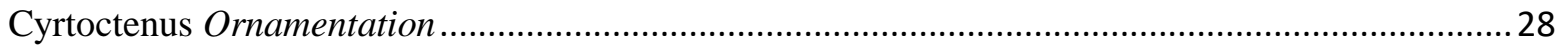

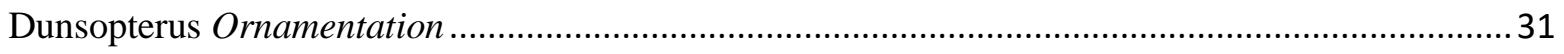

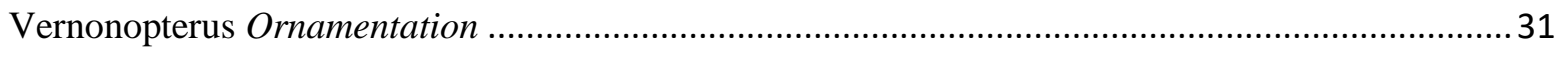

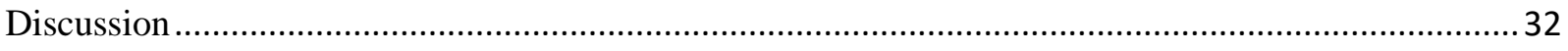

Possible Development of Comb Rachis Armature in Hibbertopterus .................................................34

Reexamining the Functional Morphology of Cyrtoctenus Appendage Armature ...............................35

Other Morphological Differences between Cyrtoctenus and Hibbertopterus...................................36

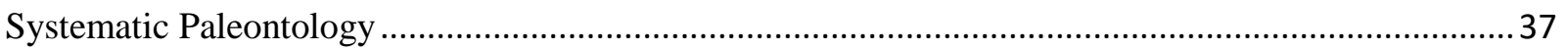

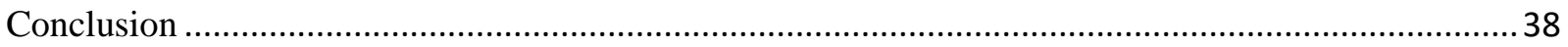




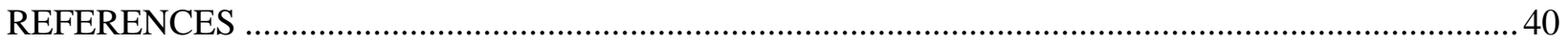

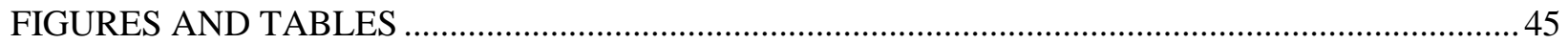




\section{CHAPTER 1- DISCERNING THE DIETS OF SWEEP-FEEDING EURYPTERIDS}

\section{Introduction}

Eurypterids were a diverse and ecologically important group of aquatic chelicerates that lived from the Middle Ordovician to the late Permian (Lamsdell and Braddy, 2010). They have been divided into two orders based largely upon the nature of their sixth appendage. The Eurypterina modified their most distal podomeres into paddles which they used for swimming, whereas the Stylonurina lacked this modification and used their sixth appendage for walking (Tetlie, 2007). Of these two clades, the Eurypterina comprise $\sim 75 \%$ of all known eurypterid species and $\sim 95 \%$ of all specimens, making the Stylonurina very rare in comparison (Tetlie, 2007). Despite their poor fossil record, stylonurines have a longer temporal range and include the youngest known eurypterids (Tetlie, 2007).

While swimming eurypterids are considered to be active predators (McCoy et al., 2015), the benthic stylonurine eurypterids appear to have had a mode of life similar to modern horseshoe crabs (Poschmann et al., 2016) with the exception of two clades, the Stylonuroidea and the Mycteropoidea, both of which independently evolved modifications for sweep-feeding on their anterior appendages (Lamsdell et al., 2010a). Rather than hunting specific individuals, sweep-feeders dragged their filtering elements through the substrate in search of prey. Both stylonuroids and mycteropoids possessed spines on their anterior prosomal appendages which they used to entrap small infaunal organisms or food particles (Lamsdell et al., 2010a). Of these two clades, the mycteropoids were more specialized sweep-feeders; rather than indiscriminately raking through the substrate, their armature included sensory setae which allowed them to detect organisms in the subsurface (Lamsdell et al., 2010a). While the stylonuroids did not survive the 
Late Devonian mass extinction, the mycteropoids radiated in the Late Devonian and persisted into the late Permian (Lamsdell et al., 2010a).

Among a diverse group of extant suspension feeders, it has been shown that there is a linear correlation between the average spacing of feeding structures and prey sizes (Figure 1) (Vinther et al., 2014). The objective of this study is to extrapolate this relationship to several sweep-feeding eurypterids in order to estimate the range of prey sizes that they could capture and to compare them to other fossil and extant forms. This research will offer insight into how eurypterid prey sizes may have changed over time, particularly during the Late Devonian mass extinction when the majority of eurypterid clades became extinct. Furthermore, this research will determine if survival rates are correlated to prey size. It is hypothesized that prey sizes decreased over time as sweep-feeding eurypterids evolved more advanced appendage armature and the success of the mycteropoids was due, at least in part, to their ability to capture smaller prey items.

\section{Materials and Methods}

Measurements of inter-armature spacing were taken from specimens stored in the National Museum of Scotland (NMS) in Edinburgh and the British Geological Society (BGS) in Nottingham. These measurements were supplemented with those of other sweep-feeding eurypterids derived from the literature (see Table 1 for a list of eurypterid specimens included in this study).

In addition to eurypterids, pectinate appendages have evolved convergently various times across several arthropod lineages, such as in numerous eumalacostracan taxa and mantid insects (Jones et al., 2018). Furthermore, pectinate claws have evolved independently multiple times in crustaceans but differ functionally from the sweep-feeding eurypterids in that they were able to 
change mesh size by varying the angle in which they held the free ramus of the claw (Tshudy and Sorhannus, 2000). However, two Late Devonian fossil decapod crustaceans bore pectinate appendages in which the spines protruded ventrally in a manner similar to the Stylonurina, and were included in this study for comparison. Maxilliped III of Palaeopaleomon newberryi (Figure 2) and maxilliped I of Angustidontus seriatus (Figure 3) were enlarged, highly spinose appendages which were capable of moving dorsal-ventrally (Jones et al., 2018). While Angustidontus is considered a pelagic predator (Rolfe and Dzik, 2006), Palaeopaleomon is believed to have raked the sediment for infaunal prey (Jones et al., 2018) like the stylonurine eurypterids.

Inter-armature spacing for the decapods Angustidontus and Palaeopaleomon were measured from the literature. Angustidontus measurements were taken from specimens NMNH 530461a, NMNH 530455, and NMNH 530453a figured in Rolfe and Dzik (2006).

Palaeopaleomon measurements were taken from specimens USNM 617308b, USNM 618374, and CMNH 4106 figured in Jones et al. (2018). The mesh sizes and estimated prey sizes of the anomalocarids Tamisiocaris borealis and Pahvantia hastata were compiled from Vinther et al. (2014) and Lerosey-Aubril and Pates (2018), respectively. The mesh and prey sizes for several modern filter feeders were also gathered from the literature. Data was extracted from text-fig. 4 of Vinther et al. (2014) using the WebPlotDigitizer application (Rohatgi, 2018). The average mesh spacing for each fossil specimen was used to infer the range of prey sizes that could be captured by applying the lower and upper bound equations from Vinther et al. (2014), which are $\mathrm{y}=1.4452 \mathrm{x}^{1.0083}$ and $\mathrm{y}=11.772 \mathrm{x}^{0.8928}$ respectively, where $\mathrm{x}$ is the average mesh spacing and $\mathrm{y}$ is the estimated prey size. 
Specimens were photographed with a Canon EOS 80D camera. The spacing between the distal ends of spines was measured with a caliper from photographs, with all measurements from individual specimens averaged before applying the prey size equations. In cases where spacing between adjacent spines varied along the length of the spines due to variation in the origination angle or significant spine curvature, multiple measurements were taken along the lengths of adjacent spines and averaged. Spacing measurements between adjacent spines were not taken in cases where it was not clear whether the individual spines originated from an anterior or posterior row on the appendage. Spacing measurements were also not taken between adjacent spines in cases where spines appeared to be missing, possibly having broken off prior to fossilization.

In the case of Cyrtoctenus armature, comb filaments appeared to be flexible with sections along the lengths of adjacent filaments often overlapping with each other. In some cases, spacing measurements could not be taken because adjacent filaments overlapped throughout their entire lengths. In specimens NMS G 1984.69.1, NMS G 1987.7.24, and BGS GSE 2127 measurements were taken from a more proximal location along the length of the filaments, closer to where they originate from the rachis and where there appeared to be less flexion and clear separation between individual filaments.

In the case of Pagea, Angustidontus, and Palaeopaleomon, shorter accessory spines were present between the significantly longer primary spines. Considering the difference in length between the accessory and primary spines, it was inferred that prey size would be largely predicated by primary spine spacing. Therefore, measurements were taken only between primary spines rather than between accessory and primary spines. Specimen BRSUG 28857 consists of a partial Drepanopterus blade with radiating setae. Adjacent setae are in contact with each other 
along most of their lengths; however, measurements were taken between the distal ends of the setae where separation was present due to their tapered ends.

In the case of the mycteropids Megarachne and Woodwardopterus, only a single blade is preserved in each of these specimens. In order to estimate their prey sizes, measurements were taken from reconstructions of their appendages. In these reconstructions, the podomeres and blade lengths were estimated from the original material. However, in these specimens, the blades appear to originate on the proximal portion of the podomere and remain in close proximity to the appendage along its entire length. This may be a taphonomic feature, and the blades may have extended outward from the appendage in life position. However, the distances between the distal end of each blade and the proximal portion of the succeeding blade were measured from the reconstructions.

\section{Terminology Used}

Appendage terminology follows Tollerton (1989). The coxae are the most proximal appendage segments (i.e. podomere 1), and the plates overlying the coxae in some species are termed 'laden'. The moveable flattened spines on the appendages of the mycteropoids are termed 'blades', while the moveable broad spines associated with the fixed comb rachises of Cyrtoctenus are referred to as 'fingers', which have highly modified, dagger-shaped scales on the posterior margin termed 'fulcra'. 'Filaments' refer to the thin spines radiating from the comb rachis of Cyrtoctenus.

\section{Appendage Morphology and Feeding Strategies of Stylonurine Eurypterids}

The Rhenopteroidea range from the Middle Ordovician to the Middle Devonian. While the appendages of Leiopterella and Stylonuroides are unknown, the armature of Brachyopterus, Kiaeropterus, and Brachyopterella, consists of short fixed spines on appendages II-IV. The 
second and third appendage pairs of Rhenopterus bore fixed spines (Lamsdell et al., 2009). The anterior position of the compound eyes in addition to the small chelicerae and short spiniferous anterior appendages prompted Waterston (1979) to conclude that rhenopteroids were generally bottom scavengers. Furthermore, Poschmann et al. (2016) analyzed the compound eyes of Rhenopterus and found it to have low visual acuity similar to that of modern horseshoe crabs. This, their small chelicerae, small overall body size, and strong walking legs led them to conclude that Rhenopterus (Figure 4) was a crawler that fed on soft and slow-moving prey, such as worms, ostracods, and thin-shelled modiolopsid bivalves.

The Kokomopteroidea consist of two families, the Silurian kokomopterids and the early Silurian to Late Devonian hardieopterids. The kokomopterids consist of Kokomopterus (Figure 5) and Lamontopterus. While only appendage V of Lamontopterus is known, the spiniferous appendages II-IV of Kokomopterus are Hughmilleria-type, the spiniferous appendage V is Lamontopterus-type, and the nonspiniferous appendage VI is Kokomopterus-type. Hardieopterus, Hallipterus, and Tarsopterella belong to the Hardieopterids and possess a spiniferous Hardieopterus-type appendage V and a nonspiniferous Hardieopterus-type appendage VI, while prosomal appendages II-IV are largely unknown (Lamsdell et al., 2009). As with the rhenopteroids, the anterior position of the compound eyes in addition to the small chelicerae and short spiniferous anterior appendages prompted Waterston (1979) to conclude that kokomopteroids were generally bottom scavengers. The central position of the large compound eyes of Hardieopterus and its short, flat prosomal appendages suggests that it was a bottom dweller that may have lived partially buried in the substrate as the flatter appendages may have been used for shoveling (Waterston, 1979). 
The Stylonuroidea ranged from the early Silurian to the Late Devonian and consist of two families: the Stylonuridae and the Parastylonuridae (Lamsdell et al., 2010a). The stylonurids had rows of fixed spines on appendages II-IV, which they are considered to have used as dragnets to indiscriminately entangle small prey within the subsurface (Lamsdell et al., 2010a). The Silurian parastylonurids are paraphyletic and consists of two genera: Stylonurella (Figure 6) and Parastylonurus. Appendages II-IV of the parastylonurids are spiniferous Hughmilleria-type with the distal podomeres each bearing a single pair of robust spines, while appendages V and VI are non-spiniferous Parastylonurus-type or Pagea-type (Lamsdell et al., 2009). However, the anterior compound eyes and the short spines of appendages II-IV of the parastylonurids suggest that they were bottom scavengers and not adapted to a sweep-feeding mode of life (Waterston, 1979).

The Stylonuridae consist of five genera: Stylonurus, Pagea, Ctenopterus, Lauriepterus (Lamsdell et al., 2010a), and Soligorskopterus (Plax et al., 2018). Their appendages are generally very long; however, the anterior prosomal appendages have not been preserved in Stylonurus specimens (Woodward, 1872). Lauriepterus and Ctenopterus belong to the early Silurian Laurieipterinae subfamily and had 6-9 pairs of fixed spines on appendages III and IV that became elongated on the distal joints (Waterston, 1962; Clarke and Ruedemann, 1912). Pagea (Figure 7) had multiple pairs of fixed spines of variable lengths on each podomere of appendages II-IV (Waterston, 1962; Lamsdell et al., 2010b). The lengths of the spines generally increase towards the distal ends of each podomere and in the posterior appendages (Waterston, 1962). However, the accessory spines and intermediate position of the eyes in Pagea led Waterston (1985) to suggest that they were trap feeders. Appendages II-IV of Ctenopterus, Lauriepterus, and Pagea are spiniferous Ctenopterus-type, while appendages V and VI are 
nonspiniferous Pagea-type. Soligorskopterus (Figure 8) occurs in the Upper Devonian and had robust prosomal appendages that increased in length posteriorly. Appendages II-IV were spiniferous Ctenopterus-type, bearing multiple rows of small spines approximately equal in length on the distal podomeres, while appendages V and VI were nonspiniferous Parastyonurustype (Plax et al., 2018).

The Mycteropoidea were larger, more specialized sweep-feeders whose anterior prosomal appendages had blades that were broad and blunt but bore numerous sensory setae (Lamsdell et al., 2010a). These blades were likely used to sweep through soft sediment with the setae feeling for small infaunal organisms (Lamsdell et al., 2010a). Mycteropoids consist of three families: Drepanopteridae, Mycteropidae, and Hibbertopteridae (Lamsdell et al., 2010a).

The drepanopterids consist of a single genus, Drepanopterus, and were basal members of the mycteropoid clade (Lamsdell et al., 2009). They range from the lower Silurian to the Upper Devonian and were small to medium sized (Lamsdell et al., 2010a). The joints of the proximal podomeres of appendages II and III had pairs of fixed spines on their ventral surfaces, while the distal podomeres had moveable, flattened blades with long setae (Figure 9) (Lamsdell, 2013). The podomeres of appendages IV-VI thickened distally and had longitudinal posterior grooves (Lamsdell, 2013), which may have been sites of muscle attachment, suggesting these appendages were used for locomotion rather than for prey capture (Jeram and Selden, 1994). Appendage III also retained Hughmilleria-type spines which indicate drepanopterids could also capture larger prey (Lamsdell et al., 2009).

The mycteropids were large Carboniferous and Permian sweep-feeders and consist of several genera: Mycterops, Hastimima, Woodwardopterus, and Megarachne (Lamsdell, 2013). However, the anterior prosomal appendages of Mycterops and Hastimima specimens have not 
been preserved (Lamsdell and Selden, 2017). Woodwardopterus and Megarachne had blades on the distal podomeres of appendages II and III (Selden et al., 2005). Like the drepanopterids, the podomeres of appendages IV-VI thicken distally and have posterior grooves (Selden et al., 2005).

Of the three mycteropoid families, the hibbertopterids were the most specialized sweepfeeders (Lamsdell et al., 2010a). They occur predominantly in the Carboniferous but range from the Late Devonian to the late Permian (Lamsdell et al., 2010a). Five genera are included within the hibbertopterids: Hibbertopterus, Cyrtoctenus, Dunsopterus, Campylocephalus, and Vernonopterus (Lamsdell, 2013). However, the prosomal appendages are well preserved only in specimens of Hibbertopterus and Cyrtoctenus, which display sweep-feeding armature on appendages II-IV (Lamsdell et al., 2010a).

Hibbertopterus (Figure 10) had shorter, more robust appendages than the drepanopterids and mycteropids (Lamsdell, 2013). The podomeres of appendages II and III bore moveable blades, while the posterior appendages had fixed spines (Waterston, 1957). The blades had sensory setae which became more densely spaced distally (Jeram and Selden, 1994; Waterston, 1957), and the podomeres of the walking limbs (appendages IV-VI) thicken distally but lack the posterior grooves found in other members of the mycteropoid clade (Jeram \& Selden, 1994).

Cyrtoctenus is the most specialized genus of sweep-feeder among the eurypterids (Lamsdell et al., 2010a). Most specimens occur in the Carboniferous, but there is one known occurrence in the Late Devonian (Tetlie, 2007). Rather than scouring the sediment for prey, Cyrtoctenus evolved specialized appendage armature capable of capturing smaller prey out of suspension (Waterston et al., 1985). While the appendage armature is almost always disarticulated, appendage IV of Cyrtoctenus wittebergensis from the Carboniferous of South 
Africa reveals that spines on the posterior-ventral surfaces of the more distal podomeres were modified into fixed rachises, which each had two rows of flexible filaments that extended anteriorly, forming comb-like structures (Figure 11) (Waterston et al., 1985). The anteriorventral surfaces of the podomeres had moveable fingers which bore fulcra on their posterior margins (Figure 11) (Waterston et al., 1985). Reconstructions of the configuration of armature on appendages II and III of Cyrtoctenus are entirely based on this specimen (Figure 12).

The method of sweep-feeding that has been proposed for Cyrtoctenus (Figure 13) is more complex than that of other Stylonurina. Waterston et al. (1985) suggested that water currents flowing parallel to the filaments of appendages II and III would be generated when the appendages were drawn towards the ventral body wall. These currents would cause the two rows of filaments on each rachis to spread open and cover a large area, allowing Cyrtoctenus to filter large volumes of water. Barbs on the distal ends of the filaments would be oriented towards the oncoming current, acting as tiny spikes which kept the filtered food particles in place. With the rows of filaments spread out, the moveable finger of the corresponding podomere would then be inserted in between them. Upon initiating the backstroke, the opposing water current would force the filaments to close around the finger at which point the finger would slide outwards, with the fulcra scraping the filaments clean and ejecting food particles into the oral region. The combs on appendage IV would have served to trap food underneath the ventral body wall.

\section{Results}

Figures 14-16 show the estimated prey size ranges of the various taxa included in this study. There were no clear trends in prey size estimates among stylonurine eurypterids or within major clades (Figure 17). The average armature spacing for most eurypterids considered to be sweep-feeders was within $2.5 \mathrm{~mm}$ to $4.6 \mathrm{~mm}$. The bottom scavenging parastylonurids and the 
pelagic predator Angustidontus had nearly identical inter-armature spacing and also fell within this range, so it is interesting to note that armature spacing is similar across these ecological roles. Soligorskopterus and Ctenopterus had smaller armature spacings of $\sim 1100 \mu \mathrm{m}$ and $\sim 860 \mu \mathrm{m}$, respectively, which is more comparable to Palaeopaleomon's inter-spine spacing of $\sim 880 \mu \mathrm{m}$. Cyrtoctenus and Pagea were outliers, with $C$. peachi having the smallest average filament spacing of $\sim 67 \mu \mathrm{m}$ and $P$. sturrocki had the largest spacing of $\sim 7.7 \mathrm{~mm}$. The accessory spines and intermediate position of the eyes in Pagea led Waterston (1985) to suggest that they were trap feeders, and this may explain why its armature spacing is so large in comparison to the other stylonurines.

\section{Discussion}

\section{Possible Prey Items of Sweep-Feeding Eurypterids}

These results suggest that the prey sizes that most stylonurines could capture with their appendage armature were very similar, and thus had very similar diets. Excluding the outlying Cyrtoctenus and Pagea values, the average armature spacing of a sweep-feeding stylonurine eurypterid was $\sim 3 \mathrm{~mm}$ which provides an average prey size diameter of $\sim 4 \mathrm{~mm}$ to $\sim 40 \mathrm{~mm}$. This suggests that the armature of the sweep-feeding Stylonurina was optimally suited for capturing small macrofauna. Benthic macroinvertebrates such as crustaceans, mollusks, and trace fossils attributed to worm-like organisms are commonly found in association with eurypterids and would be manageable prey items (Størmer and Waterston, 1968; Clarkson et al., 1994; Clarkson et al., 2009). The smaller armature spacing of Soligorskopterus and Ctenopterus suggests that they could also capture smaller food particles, such as benthic algae and larvae.

\section{Feeding Strategies of the Stylonurine Eurypterids}

In addition to appendage armature, multiple aspects of eurypterid morphology, such as eye position, body size, and masticatory processes may provide key insights into their diets and 
mode of predation (Waterston, 1979). The mode of life of the swimming Eurypterina contrasts with that of the Stylonurina, whose long posterior appendage pairs indicate that they were benthic crawlers or walkers. Although several Eurypterina such as Mixopterus and Megalograptus also possessed spiniferous anterior appendages, Waterson (1979) stated that they cannot be compared functionally to the spiniferous appendages of the Stylonurina; the anterior appendages of these Eurypterina are clearly indicative of an active form of predation in which the forward-facing spines were used in active prey capture. This is in contrast to the Stylonurina, whose armature protrudes from the ventral surfaces of the podomeres, indicating food was collected beneath their prosoma. Thus, in the case of the stylonuroids and mycteropoids, it has been suggested that the anterior appendage armature was used to rake through the substrate in search of infaunal organisms (Lamsdell et al., 2009). However, if they were able to externally rotate their appendages so that their armature was directed anteriorly, they may have been capable of actively trapping prey as well.

Although morphological aspects of stylonurine eurypterids may indicate an inclination to one particular feeding strategy, they may have been generalized feeders and not specialized for just one form of prey capture or food collection. In order to explain the occurrence of specific trace fossils in the Devonian Campbellton Formation of New Brunswick, Canada, King et al. (2017) proposed that, in addition to active prey capture, Pterygotus also used its denticulate chelicerae to rake the substrate for prey. Additionally, modern crayfish are known to employ several feeding strategies including active predation, foraging, and scavenging (Longshaw and Stebbing, 2016). This may have also been the case with the stylonurine eurypterids. For example, Drepanopterus prosomal appendages retained the Hughmilleria-type conical spines in addition to developing blades suitable for raking through the substrate. Therefore, Drepanopterus may 
have been capable of collecting smaller infaunal organisms in addition to larger invertebrates (Lamsdell et al., 2009).

The similar average armature spacings of the supposedly sweep-feeding stylonurines were very comparable to the scavenging parastylonurids and Angustidontus, a predatory pelagic crustacean (Figures 14-15). Thus, it may be the case that these eurypterids were not specifically adapted to a sweep-feeding mode of life and were more generalized feeders. In addition to scavenging, they may have been capable of piercing and trapping nektonic organisms with their appendage armature. Furthermore, the larger inter-armature spacing of Pagea, in particular, suggests that it was not a sweep-feeder, but rather used its spiniferous appendages to trap prey, with the long primary spines likely impaling organisms while the smaller accessory spines would have prevented its victims from struggling free.

The hibbertopterids, however, do appear to be specialized for sweep-feeding. The broad, blunt spines of Hibbertopterus which bore sensory setae were clearly not suitable for piercing or grasping prey, nor were the thin and flexible filaments of Cyrtoctenus which were clearly adapted for straining the water for fine organic particles. However, Cyrtoctenus retained narrow gnathobasic teeth similar to those of Hibbertopterus, indicating Cyrtoctenus could still masticate larger food items or crush up harder shell material (Lamsdell et al., 2009).

\section{Eurypterids and Modern Filter Feeders}

Cyrtoctenus sp. (NMS G 1987.7.24) and Cyrtoctenus dewalquei had nearly identical prey size estimates that range from $0.60 \mathrm{~mm}$ to $7.3 \mathrm{~mm}$, which corresponds to a diet of mesoplankton and is very similar to the estimated prey sizes of the anomalocarid Tamisiocaris (Figure 16) (Vinther et al., 2014). This prey size range also overlaps with those of the greater flamingo, anchovy, and rainbow trout. The greater flamingo commonly preys upon small crustaceans such 
as isopods and brine shrimp (Jenkins, 1957). Anchovy feed primarily on ostracods (Tanaka et al., 2006), while cladocerans are the dominate diet staple of rainbow trout (Budy and Haddix, 2005). Carbonita ostracods were abundant in the Midland Valley of Scotland during the Carboniferous and fall within the estimated prey size range of Cyrtoctenus (Bennett et al., 2011). Filter-feeding fish such as acanthodians are often found in association with Cyrtoctenus and may have competed with it for similar prey items (Størmer and Waterston, 1968; Evans, 1999). However, Cyrtoctenus may have been able to avoid competition with these fish to some extent by feeding in lake margins.

The estimated prey size range of Cyrtoctenus peachi is most comparable to that of the anomalocarid Pahvantia (Lerosey-Aubril and Pates, 2018) and the Andean flamingo Phoenicoparrus andinus, which has a reported mesh size of $\sim 60 \mu \mathrm{m}$ and a diet dominantly comprising diatoms that range in size from $0.1 \mathrm{~mm}$ to $2 \mathrm{~mm}$ (Jenkin, 1957). Andean flamingos feed along the margins of lagoons and saline lakes by sweeping their bills across the surface of the substrate in order to suspend small food particles which can then be filtered by the lamellae within their bills as water is pumped through the oral region by the motion of the tongue (Jenkin, 1957). It is noteworthy that flamingos and Cyrtoctenus both occupied marginal and lacustrine environments, and perhaps the appendages and moveable fingers of Cyrtoctenus were used to disturb the substrate in order to suspend food particles which could then be filtered by the combs, much like how flamingos sweep their bills over the substrate to suspend benthic diatoms (Jenkin, 1957).

Andean flamingos commonly feed in saline lakes because the water chemistry allows large populations of algae and zooplankton to thrive which can support large flocks (Jenkin, 1957). While most sweep-feeding Stylonurina occur in fresh to brackish water environments, 
Soligorskopterus is associated with hypersaline deposits of Belarus. Although Soligorskopterus likely did not take up permanent residence in hypersaline water bodies (Plax et al., 2018), its closely spaced appendage armature compared to most other eurypterids may have been an adaptation for feeding on the smaller organisms that may have been abundant in saline water bodies.

\section{Eurypterids and the Late Devonian Mass Extinction Event}

After enduring the Ordovician mass extinction, eurypterids radiated in the Silurian (Lamsdell and Selden, 2017). However, decreased speciation rates in the Devonian caused diversity to decline significantly, and their lack of recovery after the Late Devonian mass extinction may have been due to their reduction in ecospace after transitioning to fresh water environments (Lamsdell and Selden, 2017). Decreased origination rates in the Late Devonian have been attributed to marine transgressions which facilitated range expansions and the invasion of species which ultimately reduced instances of vicariant speciation (Lamsdell and Selden, 2017).

During the Late Devonian mass extinction, the Eurypterina suffered major losses (Figure 18), and only the Adelopthalmidae persisted into the Carboniferous (Romer, 1933; Lamsdell and Braddy, 2010). Their decline may have been linked to increased competition with jawed fish, such as the placoderms, which underwent a major radiation in the Devonian (Lamsdell and Braddy, 2010). Furthermore, abiotic factors such as marine transgressions may have reduced instances of endemism, resulting in a decline in speciation rates as background extinctions continued to reduce their diversity throughout the Devonian (Lamsdell and Selden, 2017). The Stylonurina fared much better, and their diversity was relatively stable throughout the Devonian (Lamsdell and Braddy, 2010). During the Late Devonian and Carboniferous, mycteropoid 
diversity increased, and they underwent the last major eurypterid radiation (Tetlie, 2007).

Mycteropids and the hibbertopterids were the only Stylonurina to persist into the late Paleozoic, and they attained a more global distribution after the formation of Pangea (Tetlie, 2007). Their success has been attributed to their sweep-feeding more of life which allowed them to avoid competition with nektonic predators (Lamsdell and Braddy, 2010).

\section{Phylogenetic Trends in Prey Size}

It was hypothesized that as sweep-feeding eurypterids evolved more advanced armature, they would have developed finer prey capture abilities. However, there are no obvious trends in prey size among stylonurine eurypterids or within major clades (Figure 17). While the scavenging kokomopteroids had the largest average inter-armature spacing among the four major stylonurine clades $(1.56 \mathrm{~cm})$, the scavenging rhenopteroids had the smallest $(1.7 \mathrm{~mm})$, which is most likely due to their particularly small body size. Furthermore, there was no clear distinction in average armature spacing among the stylonuroids $(3.1 \mathrm{~mm}$ for parastylonurids and $3.4 \mathrm{~mm}$ for stylonurids). While the mycteropoids do have a smaller average inter-armature spacing than the stylonuroids $(2.9 \mathrm{~mm}$ and $3.3 \mathrm{~mm}$, respectively), this does not hold true if the outlying Cyrtoctenus values are excluded $(3.5 \mathrm{~mm})$. Among the mycteropoids, the hibbertopterids have the smallest inter-armature spacing $(1.4 \mathrm{~mm})$ as was expected from these highly specialized sweepfeeders, but there is no trend in average mesh size across the three mycteropoid families $(3.6 \mathrm{~mm}$ for drepanopterids and $4.0 \mathrm{~mm}$ for mycteropids). These results suggest that prey size does not mediate survival in the Late Devonian and the success of the mycteropoids in comparison to the stylonuroids cannot be attributed to finer prey capture abilities.

\section{Possible Factors Influencing Survival Rates}

Although eurypterids may have originally been driven to brackish and freshwater habitats temporarily to avoid predators while they molted (Braddy, 2001), chasmataspids (Lamsdell and 
Briggs, 2017), xiphosuran (Lamsdell, 2016), and several eurypterid groups (Lamsdell and Braddy, 2010) independently transitioned to freshwater environments in the Devonian (Lamsdell et al., 2017). Because multiple groups were shifting into freshwater environments, large, widespread environmental changes must have been occurring at this time. Their transition from marine environments may have been facilitated by the high temperatures in the Devonian as most of the continental land masses were positioned at low latitudes. Studies of modern crabs have revealed that there is a greater tolerance to lower salinity environments in warmer temperatures (Anger, 1991). The transition to freshwater may have also been a case of ecological opportunism.

In order for sweep-feeding eurypterids to have taken up permanent residence in freshwater environments, a benthic fauna must have been established in fluvial and lacustrine settings by this time. Trace fossil evidence suggests that fluvial channels and marginal lacustrine environments were first invaded by benthic invertebrates in the Devonian. During the Carboniferous, a more diverse detritus-feeding epifauna and shallow infauna became established in lacustrine environments (Figure 19). The timing of this invasion has been attributed to the influx of nutrients into nonmarine aquatic habitats from the dispersal of land plants (Buatois et al., 1998). It is noteworthy that this invasion into freshwater habitats by the benthos coincides with the radiation of the predominantly freshwater sweep-feeding mycteropoids, whose success was likely strongly contingent on the availability of such benthic prey items.

Another factor that may have contributed to the success of the mycteropoids was their geographic range. The mycteropoids were able to achieve a much larger spatial distribution than the stylonuroids, and the total range of the hibbertopterids in particular was quite extensive. Cyrtoctenus had the largest range among all genera which extended from Southern Gondwana to 
the present day Czech Republic (Dunlop et al., 2015). Perhaps the survival of the hibbertopterids into the late Permian was partly due to their wide distribution which would have reduced the likelihood of random events causing their extinction.

\section{Sources of Error}

These prey size estimates were based upon suspension feeders and may underestimate the true prey size of sweep-feeding eurypterids because their appendages would have been more powerful and robust than the typical filtering structures of organisms that strain the water for food particles. Furthermore, fossil material with preserved appendage armature was limited for most taxa, and very few individuals from each species were available for inclusion in this study. Excluding the hibbertopterids which may have developed combs capable of collecting food particles out of suspension in later molt stages, prey sizes likely increased through ontogeny as individuals achieved larger body sizes. Taking these factors into account, the estimated prey sizes likely do not envelop the entire spectrum of prey sizes consumed by sweep-feeding eurypterids.

Because of the flexibility of the comb filaments of Cyrtoctenus, they likely spread outwards as the appendages were swept towards the ventral body wall due to the opposing water current that was generated. Thus, their mesh sizes may have been underestimated. In order to approximate the maximum inter-filament spacing, the dimensions of the fulcra of the associated moveable fingers were measured. If the fulcra of the moveable fingers were inserted between the filaments in order to scrape them clean and eject captured prey into the oral region, as has been suggested by Waterston (1985), the fulcra may provide a reliable approximation of maximum filament spacing. The average width of these fulcra in specimens BGS 599, BGS GSE 2184, BGS GSE 2186, and BGS GSE 9682 was $0.56 \mathrm{~mm}$, which provides a prey size estimate of 
$0.79 \mathrm{~mm}$ to $9 \mathrm{~mm}$. Even taking into account this maximum estimate of armature spacing,

Cyrtoctenus still has the smallest estimated prey sizes among all Stylonurina and still falls within the mesoplankton size range.

\section{Conclusions}

The majority of eurypterids were found to have very similar armature spacing, and there was not an obvious distinction between those considered to be sweep-feeders and the bottom scavenging parastylonurids. However, the scavenging rhenopteroids generally had more closely spaced armature, but this can be attributed to their smaller body sizes. The kokomopteroids had larger armature spacing as would be expected from these non-sweep-feeders. Among those eurypterids generally considered to be sweep-feeder, only Cyrtoctenus, Ctenopterus, Soligorskopterus, and Pagea had an inter-armature spacing outside a range of $2.5 \mathrm{~m}$ to $4.6 \mathrm{~mm}$, which corresponds to a prey size range of $3.6 \mathrm{~mm}$ to $58 \mathrm{~mm}$. This suggests that the armature of the sweep-feeding stylonuroids was optimally suited for capturing small macrofauna. Benthic macroinvertebrates such as small crustaceans, mollusks, and worm-like organisms would be manageable prey items. The smaller armature spacing of Soligorskopterus and Ctenopterus suggests that they could also capture smaller food particles, while the larger inter-armature spacing of Pagea may suggest that it was a trap feeder rather than a sweep-feeder.

The similarity of armature spacing among eurypterids with presumably different ecological roles and the lack of more advanced modifications for sweep-feeding like those found in the hibbertopterids, suggests that they may have been more generalized feeders. In addition to scavenging, they may have been capable of trapping organisms with their spiniferous appendages. Cyrtoctenus was clearly a specialized sweep-feeder and has an estimated prey size 
range indicative of a diet of mesoplankton. This prey size range is most similar to those of filterfeeding fish like anchovy and rainbow trout, as well as the Andean flamingo P. andinus.

The results of this study do not support the hypothesis that prey sizes among sweepfeeding eurypterids decreased over time, and prey size does not appear to mediate survival in the Late Devonian. While the success of the hibbertopterids may have been due to their wide distribution and sweep-feeding mode of life which allowed them to avoid competition with nektonic predators, mycteropoids as a whole likely benefited from the expanding benthos, which was invading freshwater environments in the Devonian and Carboniferous. 


\section{CHAPTER 2- EVALUATING THE POSSIBILITY OF SYNONYMY AMONG HIBBERTOPTERID EURYPTERIDS}

\section{Introduction}

In the fossil record, populations of eurypterids often appear to be segregated with juveniles commonly inhabiting marginal marine environments while adults are typically found in offshore facies (Braddy, 2001). For freshwater taxa, the absence of small juveniles among populations of larger individuals led Jeram and Selden (1994) to suggest that they developed separately in isolated nursery pools where they would be free from predation before undertaking terrestrial excursion to nearby water bodies. The frequent absence of co-occurring juvenile and adult eurypterids has made the study of eurypterid ontogeny particularly challenging, and the relatively few studies which have analyzed eurypterid development have been restricted to rare instances in which multiple instars co-occur (Lamsdell and Selden, 2013). Because of these difficulties, ontogenetic variation is rarely considered in eurypterid taxonomy and they may be oversplit as a result (Lamesdell and Selden, 2013); such may be the case particularly among the Mycteropoidea.

Mycteropoids were large, benthic eurypterids that range from the early Silurian to the late Permian. They consist of three families: Drepanopteridae, Mycteropidae, and Hibbertopteridae (Lamsdell et al., 2010a). Mycteropoids had blades on appendages II-III (and IV in Hibbertopteridae) that bore numerous sensory setae which may have been used for sweepfeeding (Lamsdell et al., 2010). Freshwater mycteropoids radiated in the Late Devonian and Carboniferous, and they were one of only two groups of eurypterids that persisted into the late Paleozoic (Lamsdell and Braddy, 2010). 
Because of the difficulties in studying eurypterid ontogeny and the lack of complete specimens for most taxa, the systematic relationships among mycteropoids are not entirely clear, and there may be several cases of synonymy particularly among the mycteropids and hibbertopterids. It has been suggested that the mycteropid genera Mycterops, Megarachne, and Woodwardopterus, are synonymous because one of the few distinctions among them is the ornamentation on their enlarged tergites and carapaces (Selden et al., 2005). The mucrones (triangular scales) become less densely spaced in Mycterops, Woodwardopterus, and Megarachne, respectively which may simply be an ontogenetic character since spacing between ornamentation structures is expected to increase with increasing body size (Selden et al., 2005).

Of the three mycteropoid families, the hibbertopterids were the most specialized sweepfeeders (Lamsdell et al., 2010a). They occur predominantly in the Carboniferous but range from the Late Devonian to the late Permian (Lamsdell et al., 2010a). Five genera are included within the hibbertopterids: Hibbertopterus, Cyrtoctenus, Dunsopterus, Campylocephalus, and Vernonopterus (Lamsdell, 2013). However, the prosomal appendages are well preserved only in specimens of Hibbertopterus and Cyrtoctenus, which display sweep-feeding armature on appendages II-IV (Lamsdell et al., 2010a).

Hibbertopterus had shorter, more robust appendages than the drepanopterids and mycteropids (Lamsdell, 2013). The podomeres of appendages II and III bore moveable blades, while the posterior appendages had fixed spines (Waterston, 1957). The blades had sensory setae which became more densely spaced distally (Figure 10) (Jeram and Selden, 1994; Waterston, 1957). Cyrtoctenus is the most specialized genus of sweep-feeders among the mycteropoids. Cyrtoctenus species had two rows of flexible filaments extending anteriorly from rachises forming comb-like structures (Waterston et al., 1985). The rachises were associated with 
moveable spines on the anterior-ventral sides of the podomeres, which would scrape the filaments and eject trapped food particles into the oral region (Figure 13) (Waterston et al., 1985).

It has been suggested that the hibbertopterid genera Dunsopterus, Cyrtoctenus, and Vernonopterus are synonymous as well (Jeram and Selden, 1994). Cyrtoctenus is paraphyletic with respect to Dunsopterus (Lamsdell and Selden, 2017), and Lamsdell (2013) noted that they possess similar prosoma, tergite, appendage, and ornamentation characteristics, while Vernonopterus and Cyrtoctenus possess similar ridges on their opisthosomas. Although no Dunsopterus or Vernonopterus specimens have been found with intact combs, Cyrtoctenus combs have been found in association with Dunsopterus and Vernonopterus (Lamsdell, 2013).

Hibbertopterus and Cyrtoctenus specimens frequently co-occur and no Cyrtoctenus specimens represent small individuals. Furthermore, as Hibbertopterus grew, the spacing between the blades on its prosomal appendages would have widened, restricting it to larger, less abundant infaunal prey if it did not modify its appendage armature (Jeram and Selden, 1994). Therefore, Hibbertopterus may be a juvenile form of Cyrtoctenus in which case the comb-like rachises did not develop until the late stages of ontogeny and juveniles retained the broad blades suitable for probing for prey in soft sediment but incapable of capturing smaller prey out of suspension. If supported, this synonymy indicates the occurrence of an ontogenetic niche shift as adult individuals became capable of capturing smaller prey as the rachises developed.

If Hibbertopterus is in fact a juvenile form of Cyrtoctenus, most Hibbertopterus specimens may represent molts which would have been subjected to less scavenging and predation than Cyrtoctenus specimens, which presumably represent mortalities (Lamsdell et al., 2010a). Furthermore, larger specimens may disarticulate more easily which would explain why 
Hibbertopterus specimens are often much more complete than Cyrtoctenus specimens (Lamsdell et al., 2010a).

\section{Eurypterid Ontogeny}

Ontogenetic changes in the prosomal appendages have been observed in several eurypterid species. These changes include varying degrees of positive allometry among the denticles of the free ramus of the chelicera in Jaekelopterus howelli (Lamsdell and Selden, 2013); shortening of the prosomal appendages in Strobilopterus proteus (Lamsdell and Selden, 2013), Eurypterus remipes (Andrews et al., 1974), Drepanopterus pentlandicus (Lamsdell, 2013), and 'Carcinosoma' scorpioides (Woodward, 1868); and enhanced curvature of the terminal podomere of Drepanopterus pentlandicus (Lamsdell, 2013). Ontogenetic changes in the paddles of 'Carcinosoma' scorpiodes, Strobilopterus princetoni, and Pentecopterus decorahensis have also been documented (Woodward, 1868; Lamsdell and Selden, 2013; Lamsdell et al., 2015).

Pentecopterus decorahensis displays the greatest degree of ontogenetic change in appendage armature (Lamsdell et al., 2015). While juvenile prosomal appendages II-IV are homonomous, they become highly differentiated in later instars, and the locations and relative proportions of the denticulations, moveable ventral spines, and fixed lateral spines change significantly (Figure 20) (Lamsdell et al, 2015). Given the degree of appendage armature reconfiguration exhibited by Pentecopterus decorahensis, the development of comb-like rachises in Hibbertopterus would not be unprecedented.

\section{Paleoecology}

Although some sweep-feeding eurypterids have been found in terrestrial and marginal lake facies, the large size of Hibbertopterus and Cyrtoctenus suggest that they were not fully 
terrestrial although their robust legs and the presence of subaerial tracks (Whyte, 2005) indicates that they were capable of short terrestrial excursions and likely migrated between seasonal pools and lakes to feed or to avoid predators while they molted (Waterston, 1968; Jeram and Selden, 1994; Braddy, 2001). However, the available evidence suggests that they only fed in aqueous environments because they lack a pre-oral cavity, which would have been necessary for feeding on land (Trewin and McNamara, 1995). They also retain gnathobases which do not function on land and are not found in any terrestrial arthropods. Their large bodies and short, robust walking legs suggest that they were slow moving, benthic animals. Hibbertopterids likely occupied estuaries, lake margins, and seasonal pools and traversed from one water body to another (Waterston, 1968; Jeram and Selden, 1994).

In hibbertopterids, the tactile moveable blades would have been used to detect organisms in the substrate (Lamsdell et al., 2009), while the central position of the lateral eyes on the posterior half of the carapace would have provided these animals with an upward field of vision to detect predators (Figure 21). Additionally, Cyrtoctenus possessed an anterior-median carapace protrusion which is further evidence that it was a bottom dweller as it would have afforded dorsal protection of the anterior appendages during sweep-feeding (Waterston et al., 1985). However, it may have also facilitated molting by increasing the size of the prosomal sutures.

\section{Ontogenetic Niche Shifts}

Hibbertopterus and Cyrtoctenus frequently co-occur (Dunlop et al., 2015) but their estimated prey size ranges are distinct, and therefore they likely occupied different niches. Their estimated prey sizes suggest that Hibbertopterus fed upon small infaunal organisms (Figure 15), while Cyrtoctenus filtered food particles out of suspension (Figure 16). If Hibbertopterus and 
Cyrtoctenus are synonymous and represent different ontogenetic stages, this distinction in prey

size would have allowed them to inhabit the same environments while avoiding competition with each other. The greater and lesser flamingos also inhabit the same environments and are a modern example of how large flocks of two different sweep-feeding forms can feed in the same lake without competing with each other due to their distinct prey sizes (Jenkin, 1957). Komodo dragons also undergo an ontogenetic niche shift; juveniles are arboreal and highly active foragers that prey upon small lizards and insects, whereas ground-dwelling adults are less active and employ a sit and wait hunting strategy directed towards larger prey like deer and pigs. This niche differentiation augments survival rates by allowing juveniles to avoid competition with adults while also evading ground-dwelling predators (Purwandana et al., 2016).

\section{Materials and Methods}

In order to assess the possibility of synonymy among the hibbertopterids, the ornamentation of Hibbertopterus, Cyrtoctenus, Dunsopterus, and Vernonopterus was compared. Specimens from the National Museum of Scotland (NMS) and the British Geological Survey (BGS) were studied directly. Detailed descriptions and figures of H. scouleri, C. peachi, C. dewalquei, C. wittebergensis, D. stevensoni, and V. minutisculptus were also compiled from the literature. Ornamentation terminology follows Tollerton (1989).

\section{Results}

\section{Hibbertopterus Ornamentation}

The most complete material among this genus belongs to H. scouleri from the Carboniferous of Scotland. Fine granular ornamentation is present on the marginal shields and on the anterior portion of the prosoma. Posteriorly directed mucrones are present between the lateral eyes and on the posterior-lateral angles (Figure 22). These mucrones become narrower and asymmetric laterally. The posterior margin of the prosoma has longitudinal, linear ridges and 
mucrones, and the marginal rim consists of small rounded lunules. There are pores along the marginal rim and in the centers of many mucrones in the post ocular area (Waterston, 1957).

The anterior half of the metastoma is adorned with linguiform scales. These scales are directed towards the center of the metastoma. The appendages have small, less pronounced linguiform scales directed distally. The blades of appendages II and III become densely ornamented distally with spirally arranged polygonal cuticular thickenings which bear pores (Figure 10). These pores were likely folliculated with sensory hairs which may have had a tactile or chemosensory function (Waterston, 1957).

NMS G 1987.7.10 is likely a tibia of H. scouleri and is densely ornamented with linguiform scales (Figure 23) (Jeram and Selden, 1994). GSE 12277 (Figure 24) is a fragmentary prosomal appendage assigned to Hibbertopterus and bears scattered linguiform scales surrounded by a reticulate pattern of shallow grooves on the dorsal surface. The scales become more mucronate and abundant anteriorly and distally. The sizes differ, but the larger ones bear pores. The anterior distal margin is crenulated by linguiform scales which increase in size anteriorly. The ventral surface has a series of protruding spines near the distal margin. Mucrones occupy the anterior surface, while linguiform scales ornament the medial surface (Waterston, 1968).

The posterior sections of the mesosomal segments are each ornamented with a row of mucrones similar to the posterior boarder of the prosoma. The posterior margins of the metasomal segments have rounder, less pronounced mucrones. The ventral surfaces bear reticulate ornament, and the segments have denticulate posterior boarders, which become longer and narrower on the posterior segments (Figure 25) (Waterston, 1957). 
The tergite lateral margins are ornamented with lunules of two discrete sizes. The anterior-ventral surface of the telson has a reticulate pattern consisting of upraised areas divided into irregular polygons by shallow grooves. This ornamentation is very similar to that of the Mycterops blairi, in which the reticulate pattern transitions into large, rounded scales and interspaced minute scales on the posterior and lateral regions of the dorsal tergites (Jeram and Selden, 1994).

\section{Cyrtoctenus Ornamentation}

The ornamentation of the appendage armature of $C$. peachi from the Carboniferous of Scotland has been thoroughly described by Størmer and Waterston (1968). Both the ventral and dorsal surfaces of the combs have elongated linguiform tubercles that run parallel to the anterior margin and are directed distally (Figure 26). These become larger and more pronounced towards the anterior margin. On the distal portion of the anterior margin, the tubercles form flat, partially overlapping spines which are directed distally.

The ornamentation and morphology of the moveable fingers, which are believed to be associated with comb rachises, varies among the Scottish specimens, and Størmer and Waterston (1968) categorized them into several types (Figure 27). The ventral surface of type B has lunules that become smaller and more elongated distally. Some of these scales bear pores, and the scales along the posterior margin develop into fulcra which become more elongated and densely spaced distally. The dorsal surface bears scattered elongated scales on the anterior margin which become more lunular distally and at the posterior margin. Short filaments protrude at the posterior margin and the scales on the anterior margin are linguiform (Størmer and Waterston, 1968).

The ventral surface of type $\mathrm{C}$ bears lunular to elliptical shaped scales directed distally. These become less pronounced towards the anterior margin. On the dorsal surface, there are 
small, triangular scales similar to those found on the comb and the dorsal surface of the type B finger. On the ventral surface of type $\mathrm{D}$, large scales gradually develop distally along the posterior border and are lunular to linguiform. The distal posterior boarder bears larger lunules, many of which are folliculated. The scales decrease in size anteriorly, and the anterior margin bears three short spines that are directed distally. The ventral surface has scattered lunules at the distal end. Many elongated scales at the posterior margin have pores and develop into fulcra (Størmer and Waterston, 1968).

The ventral surface of type $\mathrm{E}$ is covered with flat tubercles that decrease in size anteriorly. The elongated scales have a semi-circular to parabolic distal boarder, and the sides of the scales are parallel to convex which makes them more elliptical. These scales also bear pores and may develop into flat tubercles. The dorsal surface is granulated and bears scattered elongated scales. The scales decrease in size towards the anterior margin. Along the posterior margin, large scales develop into fulcra which become more elongated and crowded as in type B. Among the various finger morphologies described above, type $\mathrm{E}$ is unique in that the rachis is straighter and only a single row of fulcra protrudes from the posterior margin; no filaments are present (Størmer and Waterston, 1968).

The two main types of ornamentation observed in the appendage armature of C. peachi consist of the elongated linguiform scales which lack pores and the often folliculated parabolic scales. A clear transition from the parabolic scales to the fulcra can be seen on the moveable fingers of C. peachi. Additionally, the filaments may develop from the linguiform scales, although this transition is not as clear (Størmer and Waterston, 1968).

Cyrtoctenus wittebergensis from the Carboniferous of South Africa is a much more complete specimen in comparison to the Scottish material. The anterior margin of the brim of the 
prosoma bears pronounced densely spaced tubercles which represent the bases of moveable hairs or spines. Posteriorly, these are replaced by broad folliculated lunules that close laterally and transition into narrow lunules only some of which are folliculated. Mucrones occur on the anterior lateral regions and extend to the post lateral angles (Figure 28). Medially, these become rounded and broader, while laterally they become narrower and asymmetric. The posterior margin bears pronounced large mucrones and ridges (Waterston et al., 1985).

The distal margins of the podomeres bear coarse, rounded crenulations, and lunules surround the appendage grooves. Large, distally closing and overlapping lunules occur on the anterior margin of the podomeres. The posterior podomere regions bear large scales that are shorter and more rectangular. The moveable fingers bear folliculated cuticular thickenings (Waterston et al., 1985).

The posterior axial portions of the tergites possess pronounced lunules, longitudinal ridges, and furrows. The posterior margin is finely and irregularly crenulated, while the pleural portions are smooth. The lateral and post-lateral regions of the opercular plate bears wide, rounded asymmetrical lunules which decrease in size anteriorly and mesially. The posterior regions of the post-abdominal plates have longitudinal furrows and ridges which are most strongly developed on the posterior segments. The posterior margins are also finely and irregularly crenulated. Large narrow lunules develop post- laterally (Waterston et al., 1985).

The dorsal surface of the telson bears narrow lunules anteriorly which are symmetrical and posteriorly directed. Laterally, these become asymmetrical and post-laterally directed. They are scattered over most of the surface posteriorly, but large narrow lunules continue at the margins. The ventral surface lacks ornamentation except near the anterior lateral shoulders, 
where there are lunules, and posteriorly, where there are large narrow lunules at the margins (Waterston et al., 1985).

\section{Dunsopterus Ornamentation}

Numerous tergite fragments belonging to Dunsopterus stevensoni co-occur with Hibbertopterus and Cyrtoctenus material from Scotland (Figure 29). The posterior tergite margins are adorned with pronounced mucronate spines of variable size but are largest medially. Acute mucrones occur anteriorly and have concave lateral margins. These decrease in size anteriorly, transitioning into broad lunules then to small linear scales until the cuticle becomes smooth or granular. The prosoma is also ornamented with mucrones which become elongated and narrower posteriorly to form pronounced mucronate spines on the posterior margin. Podomeres from the proximal portions of posterior walking legs bear widely spaced linguiform scales anteriorly and ventrally, while fine granular ornamentation appears posteriorly and dorsally (Figure 30). The proximal margin is densely ornamented with flattened tubercles (Waterston, 1957).

\section{Vernonopterus Ornamentation}

The ventral plates of Vernonopterus minutisculptus are finely granulated and small scales develop near the posterior borders. The dorsal tergites bear pronounced ornamentation in their medial portions which consist of semi-lunar scales that are evenly distributed anteriorly, but posteriorly they become oriented into longitudinal tracts composed of larger scales (Figure 31). These rows of scales protrude at the posterior tergite margins, forming large crenulations. These occur within the median regions of the tergites and become more pronounced laterally, terminating in spines at the posterior margins. Smaller scales occur between these rows, and the pleural portions of the tergites are adorned with minute scales (Waterston, 1957). 


\section{Discussion}

The ornamentation of Hibbertopterus generally conforms to that of Cyrtoctenus. Both possess folliculated pustules on the anterior portions of their carapace which transition into mucrones posteriorly, some of which are also folliculated. These mucrones also become smaller and asymmetric laterally in both taxa. Some of the ventral plates of these two taxa -the metastoma of Hibbertopterus and the opercular plate of Cyrtoctenus- are ornamented with lunules. The posterior margins of the tergites are similarly crenulated with a row of mucrones, which become more pronounced on posterior segments. However, the marginal mucrones of Cyrtoctenus are larger and more pronounced than in Hibbertopterus. Co-occurring tergite fragments of Dunsopterus stevensoni also have very pronounced mucronate ornamentation along the posterior margins. As with all material assigned to Cyrtoctenus, the size of these Dunsopterus tergite fragments suggest that they belonged to large individuals, so perhaps the mucrones along the posterior margins grew allometrically through ontogeny.

The ornamentation of Dunsopterus is also consistent with Cyrtoctenus and Hibbertopterus, with mucrones increasing in size posteriorly on the prosoma and tergites and with posteriorly directed linguiform scales occurring on the podomeres, particularly on the anterior portions. However, the linguiform appendage ornamentation is more widely spaced in Dunsopterus (Waterston, 1968), but this is likely due to its location on a proximal segment of a walking leg and its large size. As individuals grew, the spacing between the scales likely increased through ontogeny. Another minor difference between Dunsopterus and Hibbertopterus is that some of the mucrones of Dunsopterus often have concave lateral edges whereas the sides of the mucrones of Hibbertopterus were straight (Waterston, 1957). However, tergite fragments possibly belonging to Cyrtoctenus dewalquei from Belgium show a transition from lunules to 
"keyhole" shaped scales as the lateral margins of the scales become increasingly concaved (Figure 32) (Størmer and Waterston, 1968).

In Cyrtoctenus, the ornamentation of the lateral regions of the tergites appears to differ with Hibbertopterus. Opisthosomal ridges divide the dorsal tergites into axial and pleural regions, which is a feature not present in Hibbertopterus. While Vernonopterus also has a series of longitudinal ridges which divide the tergites into axial and pleural regions, these ridges consist of scales and are not simply up-folds of the tergites themselves. Furthermore, among the eurypterids examined, the ornamentation of Vernonopterus is distinct. It lacks mucrones and the parabolic scales of the tergites are uniquely oriented into discrete rows; such features argue against synonymy with the other hibbertopterids.

Cyrtoctenus and Hibbertopterus have further differences in ornamentation. The cuticle of the pleural regions of the tergites is relatively smooth in $C$. wittebergensis, while the crenulated posterior margins appear to extend to the lateral margins of the tergites in Hibbertopterus. Furthermore, the ventral surface of the telson of Cyrtoctenus is ornamented with lunules, while the ventral surface of the telson of Hibbertopterus bears a reticulate pattern very similar to Mycterops blairi. However, these differences could be attributable to ontogeny because the telson morphology has been shown to change through development in Drepanopterus (Lamsdell, 2013). Furthermore, while these differences do not seem to support synonymy, the $C$. wittebergensis specimen from South Africa represent a rare instance in which it does not cooccur with Hibbertopterus material, and thus minor morphological differences with the Scotland hibbertopterids is not surprising.

The ornamentation of the appendages of Hibbertopterus and Cyrtoctenus are consistent. Both are decorated by folliculated pustules which become more densely space distally on the 
blades of Hibbertopterus and on the fingers of Cyrtoctenus. This should be regarded as a particularly important feature, as the fulcra and filaments of Cyrtoctenus armature appears to be derived from its linguiform ornamentation (Størmer and Waterston, 1968). So, if Hibbertopterus were to develop comb rachis and moveable fingers later in ontogeny, it should possess very similar appendage ornamentation. However, the distal margins of the Cyrtoctenus podomeres are crenulated which is a feature that is absent in Hibbertopterus.

\section{Possible Development of Comb Rachis Armature in Hibbertopterus}

The moveable blades of Hibbertopterus share several important similarities with the moveable fingers of Cyrtoctenus. Both structures originate from the distal margins of the ventral surfaces of the podomeres and possess folliculated cuticular thickenings often in the form of linguiform scales which become more densely spaced distally (Waterston, 1957; Størmer and Waterston, 1968; Waterston et al., 1985). Therefore, if Hibbertopterus is in fact a juvenile form of Cyrtoctenus, its moveable blades are most likely the precursors to the moveable fingers.

The combs of $C$. peachi and $C$. wittebergensis are distinct among the other armature types associated with this genus. The comb rachises are fixed structures, lacking folliculated ornamentation (Waterston et al., 1985), and are much narrower than the robust, folliculated moveable fingers. Appendage IV of Hibbertopterus has a double set of ventral spines on the posterior-distal margins of the podomeres which is consistent with the position of the comb rachis of Cyrtoctenus wittebergensis. Therefore, these spines seem to be the most likely precursor to the combs. However, it is less clear how the fixed combs may have developed on appendages II and III of Hibbertopterus, as these appendages lack fixed spines (Waterston, 1957). Perhaps such spines originated only in later stages of development. 
In addition to the movable blades on the distal margins of the podomeres, similarly ornamented blades also protrude from a medial-ventral position on the distal podomeres of the second and third appendage pairs, giving Hibbertopterus up to three blades per podomere in some cases (Figure 33) (Waterston, 1957). If all of these blades developed into moveable fingers and were each associated with its own comb rachis in later molt stages, the anterior appendage pairs in mature individuals must have been over crowded with up to six rachises per podomere. While in theory numerous filtering structures may have been necessary to collect enough nutrients to support the large body sizes typical of mature hibbertopterids, it seems unlikely that each Hibbertopterus blade on appendages II and III was retained through ontogeny and used to clean an adjacent comb rachis.

Therefore, in order to produce the configuration of armature that has been proposed for Cyrtoctenus (Waterston et al., 1985), the anterior prosomal appendages of Hibbertopterus must have undergone a more extreme form of ontogenetic change than simply developing comb rachis (Figure 34). It is possible that Hibbertopterus may have lost or reduced some of its blades in order to make room for fixed combs to develop. Alternatively, a simpler explanation is that the moveable blades themselves developed filaments suitable for collecting food particles; however, none of the known fingers possess long enough filaments to adequately strain the water for prey items like the comb rachis. Finally, combs may have been few in number or altogether absent on the anterior appendages.

\section{Reexamining the Functional Morphology of Cyrtoctenus Appendage Armature}

Finger types B, C, and D all had a row of short filaments in addition to a row of fulcra on their margins. Among the Scottish material, although the appendage armature was disarticulated, when these structures are associated with combs, they are always oriented with the row of fulcra 
and filaments directed away from the filaments of the comb, which suggests that they were not used to clean the combs. Perhaps some of the moveable blades of Hibbertopterus served a different function, such as to sweep across the substrate, disturbing the soft sediment and suspending food particles into the water so they could then be collected by the combs. In comparison to the combs, the fingers are much more robust, and their fulcra and filaments are thicker. They could have been used to scrape along the sediment, unlike the thinner, fragile filaments of the comb. Flamingoes employ a similar method as they will often disturb the bottom sediment by either sweeping their bills back a forth or by treading and stomping on the bottom surface (Jenkins, 1957).

\section{Other Morphological Differences between Cyrtoctenus and Hibbertopterus}

In addition to appendage armature, Cyrtoctenus and Hibbertopterus have several minor morphological differences. Cyrtoctenus has an anterior-median carapace protrusion, crenulated distal podomere margins, longitudinal grooves on the walking limbs, opisthosomal ridges (Waterston et al., 1985), and more centrally located eyes (Lamsdell, 2013), which are features that are all absent in Hibbertopterus. Hibbertopterus also has an inflated inter-ocular region (Waterston et al., 1985) and coxal laden which are absent in Cyrtoctenus, although the oddly shaped Cyrtoctenus coxae may be due to the fusion of the laden onto the coxae (Lamsdell et al., 2009).

Ontogenetic studies of other eurypterids provide a precedent for most of these differences. Changes in the ornamentation of the distal margins of the podomeres have been observed in Pentecopterus decorahensis (Figure 20) (Lamsdell et al., 2015). The development of a more central position of the compound eyes has been observed in specimens of Drepanopterus pentlandicus (Lamsdell, 2013) and Eurypterus remipes (Andrews et al., 1974). 
The appendage grooves have only been observed in large individuals and appear to be absent in juvenile drepanopterids (Lamsdell, 2013) which suggest they may be muscle attachment sites that support greater load bearing in adult individuals (Waterston et al., 1985). Other changes in carapace morphology such as the inflation of the inter-ocular region and the anterior-median carapace protrusion have not been observed throughout ontogeny in other eurypterids; however, the overall shape of the carapace does appear to change through development in Drepanopterus pentlandicus (Lamsdell, 2013) and Eurypterus remipes (Andrews et al., 1974).

Finally, the opisthosomal ridges of Cyrtoctenus may also be an ontogenetic feature. In Drepanopterus pentlandicus, the opisthosomal tubercles are present only in larger individuals which suggests that they developed in later molt stages; although, Lamsdell (2013) did not rule out the possibility that they could also be sexually dimorphic features. Finally, the fusion of the laden onto the coxae would seem to be a more drastic ontogenetic change.

Nevertheless, the ornamentation of Hibbertopterus, Dunsopterus, and Cyrtoctenus is largely consistent. Despite the differences between Cyrtoctenus and Hibbertopterus discussed above, the morphology of Dunsopterus conforms strongly to Hibbertopterus, and they are most likely congeneric. Furthermore, Cyrtoctenus is paraphyletic to Dunsopterus (Lamsdell and Selden, 2017); therefore, all three genera can be synonymized with Hibbertopterus having priority. However, the distinct ornamentation of Vernonopterus does not permit synonymization with any of the hibbertopterids examined in this study.

\section{Systematic Paleontology}

Order Eurypterida Burmeister, 1843

Suborder Stylonurina Diener, 1924

Superfamily Mycteropoidea Cope, 1886 
Family Hibbertopteridae Kjellesvig-Waering, 1959

Genus Hibbertopterus Kjellesvig-Waering, 1959

[=Dunsopterus Waterston, 1968; =Cyrtoctenus Størmer and Waterston, 1968]

Emended Diagnosis Hibbertopterid eurypterids in which longitudinal posterior grooves and comb rachises are present on the podomeres of adult individuals; cuticular ornament of scattered parabolic scales and mucrones (emended from Jeram and Selden, 1994).

Type Species Hibbertopterus scouleri (Hibbert, 1836)

Other Species Hibbertopterus caledonicus (Salter, 1863), Hibbertopterus dewalquei (Fraipont, 1889), Hibbertopterus dicki (Peach, 1883), Hibbertopterus ostraviensis (Augusta \& Pribyl, 1951), Hibbertopterus peachi (Størmer \& Waterston, 1968), Hibbertopterus stevensoni (Etheridge Jr., 1877), Hibbertopterus wittebergensis (Waterston et al., 1985), Hibbertopterus (?) wrightianus (Dawson, 1881), Hibbertopterus (?) hibernicus (Baily, 1872), Hibbertopterus (?) sewardi (Strand, 1926)

Remarks The characteristics specified by Størmer and Waterston (1968) and Waterston (1968) which were used to distinguish hibbertopterid genera include longitudinal posterior grooves on the walking legs (present in Cyrtoctenus and Dunsopterus) and comb rachises on the anterior appendages (present in Cyrtoctenus). However, these are likely ontogenetic features and not present in juvenile individuals. In addition to these genera, several Hibbertopterus species may be synonymous as well, but this is beyond the scope of the current work.

\section{Conclusion}

Hibbertopterus, Dunsopterus, and Cyrtoctenus possess very similar ornamentation characteristics. The strong morphological similarities between Hibbertopterus and Dunsopterus in particular warrant their synonymization. The overall form and ornamentation of the moveable 
blades of Hibbertopterus suggests that they are the precursors to the moveable fingers of Cyrtoctenus. The comb rachises of Cyrtoctenus are much thinner than the moveable fingers and lack folliculated ornamentation, suggesting that they are not derived from the same moveable blades, but rather from fixed posterior-ventral spines like those of appendage IV of Hibbertopterus.

It is unclear if combs also developed on appendages II and III of Hibbertopterus which lack fixed spines. Possible scenarios of the ontogenetic development of the crowded moveable blades on appendages II and III were discussed. Some of these blades may have become reduced or lost in order to make room for the development of fixed comb rachises. The blades may have developed filaments suitable for filtering particles from the water, although none of the available material suggests that these filaments were long enough to perform this function. Not every blade may have been associated with a fixed comb, but instead may have been used to scrape along the surface of the substrate, suspending the sediment and any small organic particles so that they could filtered by the combs. Until more complete material of the anterior appendages of Cyrtoctenus is found, actualistic models are an avenue to further investigate the scenarios proposed above.

Besides differences in appendage armature, other morphological differences between Hibbertopterus and Cyrtoctenus are minor and can also be attributed to ontogeny, sexual dimorphism, or interspecific variation. If Hibbertopterus is in fact a juvenile form of Cyrtoctenus, the development of comb rachises would have allowed adult individuals to prey upon small organic food particles, while juveniles captured larger infaunal organisms with their moveable blades. This ontogenetic niche shift would have allowed adults to avoid competition with juveniles, facilitating survival rates. 


\section{REFERENCES}

Andrews, H.E., Brower, J.C, Gould, S.J., and Reyment, R.A., 1974, Growth and variation in Eurypterus remipes DeKay: Bull Geol Inst Univ Uppsala, v. 4, p. 81-114.

Anger, K., 1991, Effects of temperature and salinity on the larval development of the Chinese mitten crab Eriocheir sinensis (Decapoda: Grapsidae): Mar. Ecol. Prog. Ser., v. 72, p. 103-110.

Augusta, J. and Pribyl, A., 1951, On the Find of a Remain of Eurypterid in the Carboniferous of Ostrava: Mem. Soc. Roy. Sci. Boheme, v. 10, p. 1-9.

Baily, W.H., 1872, in Woodward, H., ed., Monograph of the British fossil Crustacea, etc.: Paleontogr. Soc., v. 4, p. 148-151.

Bennett, C.E., Siveter, D.J., Davies, S.J., Williams, M., Wilkinson, I.P., Browne, M., and Miller, C.G., 2012, Ostracods from freshwater and brackish environments of the Carboniferous of the Midland Valley of Scotland: the early colonization of terrestrial water bodies: Geol. Mag., v. 149(3), p. 366-396, doi:10.1017/S0016756811000719.

Braddy, S.J., 2001, Eurypterid palaeoecology: palaeobiological, ichnological and comparative evidence for a 'mass-moult-mate' hypothesis: Palaeogeogr. Palaeoclimatol. Palaeoecol., v. 172, p. 115-132, doi:10.1016/S0031-0182(01)00274-7.

Buatois, L.A. and Mángano, G.M., 1993, Ecospace utilization, paleoenvironmental trends, and the evolution of early nonmarine biotas: Geology, v. 21, p. 595-598.

Buatois, L.A., Mángano, G.M., Genise, J.F., and Taylor, T.N., 1998, The ichnologic record of the continental invertebrate invasion: evolutionary trends in environmental expansion, ecospace utilization, and behavioral complexity: Palaios, v. 13, p. 217-240.

Budy, P. and Haddix, T., 2005, Zooplankton size relative to gill raker spacing in rainbow trout: Transactions of the American Fisheries Society, v. 134, p. 1228-1235, doi:10.1577/T04159.1 .

Burmeister, H., 1843, Die Organisation der Trilobiten, aus ihren lebenden Verwandten entwickelt; nebst systematischen Uebersicht aller zeither beschriebenen, Arten. G. Reimer.

Clarke, J.M. and Ruedemann, R., 1912, The Eurypterida of New York: New York State Museum Memoir, v. 14, p. 1-439.

Clarkson, E.N.K., Harper, D.A.T., Taylor, C.M., and Anderson, L.I., eds., 2009, Silurian Fossils of the Pentland Hills, Scotland: London, The Palaeontological Association, 220 p.

Clarkson, E.N.K., Milner, A.R., and Coates, A.I., 1994, Paleoecology of the Viséan of East Kirkton, West Lothian, Scotland: Trans. R. Soc. Edinb.: Earth Sci., v. 84(3-4), p. 417425.

Cope, E.D., 1886, An interesting connecting genus of Chordata: American Naturalist, v.20, p. 1027-1031.

Dawson, J.W., 1881, Notes on new Erian (Devonian) plants: Q J Geol Soci., v. 37, p. 299-308. 
Diener, C., 1924, Eurypterida. 1-26. in Diener, C., ed., Fossilium catalogus I: animalia, pars 25: W. Junk, Berlin, p. 29.

Dunlop, J.A., Penney, D., and Jekel, D., 2015, A summary list of fossil spiders and their relatives: World Spider Catalog, Natural History Museum Bern. (available at http://wsc.nmbe.ch.).

Fraipont, J., 1889, Eurypterides nouveaux du Devonien superieur de Belgique (Psammites du Condroz): Annls Soc. Geol. Belg., v. 17, p. 53-62.

Etheridge, R. Jr, 1877, On the remains of a large crustacean, probably indicative of a new species of Eurypterus, or allied genus (Eurypterus? Stevensoni), from the Lower Carboniferous Series (Cementstone Group) of Berwickshire: Q J Geol Soci., London, v. 33, p. 223-228.

Evans, F.J., 1999, Palaeobiology of Early Carboniferous lacustrine biota of the Waaipoort Formation (Witteberg Group), South Africa: Palaeont. afr., v. 35, p. 1-6.

Gueriau, P., Charbonnier, S., and Clement, G., 2014, First decapod crustaceans in a Late Devonian continental ecosystem: Paleontology, v. 57(6), p. 1203-1213. doi: 10.1111/pala.12111.

Hibbert, S., 1836, On the freshwater limestone of Burdiehouse in the neighborhood of Edinburgh, belonging to the Carboniferous group of rocks. With supplementary notes on other freshwater limestones: Trans. R. Soc. Edinburgh: Earth Sci., v.13, p. 169-282.

Jenkins, P.M., 1957, The filtering-feeding and food of flamingoes (Phoenicopteri): Philosophical Transactions of the Royal Society of London, v. 204(674), p. 401-493.

Jeram, A. and Selden, P., 1994, Eurypterids from the Viséan of East Kirkton, West Lothian, Scotland: Trans. R. Soc. Edinb.: Earth Sci., v. 84(3-4), p. 301-308, doi:10.1017/S0263593300006118.

Jones, W.T., Feldmann, R.M., Hannibal, J.T., Schweitzer, C.E., Garland, M.C., Maguire, E.P., and Tashman, J.N., 2018, Morphology and paleoecology of the oldest lobster-like decapod, Palaeopaleomon newberryi Whitfield, 1880 (Decapoda: Malacostraca): Journal of Crustacean Biology, v. 38(3), p. 302-314, doi:10.1093/jcbiol/ruy022.

King, O.A., Miller, R.F., and Stimson, M.R., 2017, Ichnology of the Devonian (Emsian) Campbellton Formation, New Brunswick, Canada: Atlantic Geology, v.53, p. 1-15, doi:10.4138/atlgeol.2017.001.

Kjellesvig-Waering, E. N., 1959, A taxonomic review of some late Paleozoic Eurypterida: Journal of Paleontology, v, 33, p. 251-256.

Lamsdell, J.C., 2013, Redescription of Drepanopterus pentlandicus Laurie, 1892, the earliest known mycteropoid (Chelicerata: Eurypterida) from the early Silurian (Llandovery) of the Pentland Hills, Scotland: Earth and Environmental Science Transactions of the Royal Society of Edinburgh, v. 103, p. 77-103, doi:10.1017/S1755691012000072. 
Lamsdell, J.C. and Braddy, S.J., 2010, Cope's Rule and Romer's theory: Patterns of diversity and gigantism in eurypterids and Paleozoic vertebrates: Biology Letters, v.6, p. 265-269, doi:10.1098/rsbl.2009.0700.

Lamsdell, J.C. and Briggs, D.E.G., 2017, The first diploaspidid (Chelicerata: Chasmataspidida) from North America (Silurian, Bertie Group, New York State) is the oldest species of Diploaspis: Geological Magazine, v. 154, p.175 -80, doi: 10.1017/S0016756816000662.

Lamsdell, J.C. and Selden, P.A., 2013, Babes in the wood - a unique window into sea scorpion ontogeny: BMC Evolutionary Biology, v. 13(98), https://doi.org/10.1186/1471-2148-1398.

Lamsdell, J.C. and Selden, P.A., 2017, From success to persistence: Identifying an evolutionary regime shift in the diverse Paleozoic aquatic arthropod group Eurypterida, driven by the Devonian biotic crisis: Evolution, v. 75, p. 95-110, doi:10.1111/evo.13106.

Lamsdell, J.C., Braddy, S.J., and Tetlie, O.E., 2009, Rediscription of Drepanopterus abonensis (Chelicerata: Eurypterida: Stylonurina) from the Late Devonian of Portishead, UK: Paleontology, v. 52(5), p. 1113-1139, doi:10.1111/j.1475-4983.2009.00902.x.

Lamsdell, J.C, Braddy, S.J., and Tetlie, O.E., 2010a, The systematics and phylogeny of the Stylonurina (Arthropoda: Chelicerata: Eurypterida): Journal of Systematic Paleontology, v. 8, p. 49-61, doi: 10 1080/14772011003603564.

Lamsdell, J.C., Braddy, S.J., Loeffler, E. J., and Dineley, D.L., 2010b, Early Devonian stylonurine eurypterids from Arctic Canada: Can. J. Earth Sci., v. 47, p. 1405-1415, doi:10.1139/E10-053.

Lamsdell, J.C., Briggs, D.E.G., Huaibao P., Liu, H. P., Witzke, B.J., and McKay, R.M., 2015, The oldest described eurypterid: a giant Middle Ordovician (Darriwilian) megalograptid from the Winneshiek Lagerstätte of Iowa: BMC Evolutionary Biology, v. 15(169), doi: 10.1186/s12862-015-0443-9.

Lerosey-Aubril, R. and Pates, S., 2018, New suspension-feeding radiodont suggests evolution of microplanktivory in Cambrian macronekton: Nature Communications, v.9 (3774), p, 1-9, doi: 10.1038/s41467-018-06229-7

Longshaw, M. and Stebbing, P., 2016, Biology and ecology of crayfish: Boca Raton, Florida, Taylor and Francis, $325 \mathrm{p}$.

McCoy, V.E., Lamsdell, J.C., Poschmann, M., Anderson, R.P., and Briggs, D.E.G., 2015, All the better to see you with: eyes and claws reveal the evolution of divergent ecological roles in giant pterygotid eutypetids: Biology Letters, v. 11, 20150564. https://doi.org/10.1098/rsbl.2015.0564.

Peach, B.N., 1883, On the occurrence of Pterygotus and a limuloid in the Caithness Flagstones and on the nature and mode of formation of "Adam's Plates": Proc. R. phys. Soc. Edinb., v. 7, p. 343-350.

Plax, D.P., Lamsdell, J.C., Vrazo, M.B., and Barbikov, D.V., 2018, A new genus of eurypterid (Chelicerata, Eurypterida) from the Upper Devonian salt deposits of Belarus. Journal of Paleontology, v. 92, p. 838-849. 
Poschmann, M., Schoenemann, B., and McCoy, V.E., 2016, Telltale eyes: the lateral visual systems of Rhenish Lower Devonian eurypterids (Arthropoda, Chelicerata) and their palaeobiological implications: Palaeontology, v. 59, p. 295-304, doi: 10.1111/pala.12228.

Purwandana, D., Ariefiandy, A., Imansyah, J.M., Seno, A., Ciofi, C., Letnic, M., and Jessop, T.S., 2016, Ecological allometries and niche use dynamics across Komodo dragon ontogeny: Sci. Nat., v., 103 (27), p. 1-11, doi: 10.1007/s00114-016-1351-6.

Rohatgi, A., 2018, WebPlotDigitizer v 4.1: A computer application for extracting data from published scatter plots: Austin, Texas, https://automeris.io/WebPlotDigitizer.

Rolfe, W.D.I. and Dzik, J., 2006, Angustidontus, a Late Devonian pelagic predatory crustacean: Trans. R. Soc. Edinb.: Earth Sci., v.97, p.75-96.

Romer, A.S., 1933, Eurypterid influence on vertebrate history: Science, v.78, p.114-117, doi:10.1126/science.78.2015.114.

Salter, J.W., 1863, On some species of Eurypterus and allied forms: Q J Geol Soci., London, v. 19 , p. 81-87.

Selden, P.A., Corronca, J.A., and Hünicken, M.A., 2005, The true identity of the supposed giant fossil spider Megarachne: Biology Letters, v. 1, p. 44-48, doi:10.1098/rsbl.2004.0272

Størmer, L.S., 1934, Merostomata from the Downtonian Sandstone of Ringerike, Norway: $S k r$. Norske Vidensk-Akad.,Mat-naturv Kl., No. 10, 125 p.

Størmer, L.S., 1936, Eurypteriden aus dem rheinischen Unterdevon: Abh. Preuss, Geol. Landesanst., N.F., h. 175, 97 p.

Størmer, L.S. and Waterston, C.D., 1968, Cyrtoctenus gen. nov., a large late Paleozoic arthropod with pectinate appendages: Trans. R. Soc. Edinb., v. 68(4), p. 63-109.

Strand, E., 1926, Miscellanea nomenclatorial: Archiv für Naturgeschichte, v. 92A (8), p. 30-75.

Tanaka, H., Aoki, I., and Ohshimo, S., 2006, Feeding habits and gill raker morphology of three planktivorous pelagic fish species off the coast of northern and western Kyushu in summer: J. Fish Biol., v. 68, p.1041-1061, https://doi.org/10.1111/j.00221112.2006.00988.x.

Terwin, N.H. and McNamara, K.J., 1995, Arthropods invade the land: trace fossils and paleoenvironments of the Tumblagooda Sandstone (?late Silurian) of Kalbarri, Western Australia. Trans. R. Soc. Edinb.: Earth Sci., v. 85, p.177-210.

Tetlie, O.E., 2007, Distribution and dispersal history of Eurypterida (Chelicerata): Palaeogeogr. Palaeoclimatol. Palaeoecol., v. 252, p. 557-574, doi:10.1016/j.palaeo.2007.05.011.

Tollerton, V.P., 1989, Morphology, taxonomy, and classification of the order Eurypterida Burmeister, 1843: Journal of Paleontology, v.63, p.642-657.

Tshudy, D. and Sorhannus, U., 2000, Pectinate claws in decapod crustaceans: convergence in four lineages: Journal of Paleontology, v.74, p. 474-486. 
Vinther, J., Stein, M., Lungrich, N. R., and Harper, D. A. T., 2014, A suspension-feeding anomalocarid from the early Cambrian: Nature, v. 507, p. 96-499, doi:

10.1038/nature13010.

Waterston, C.D., 1957, The Scottish Carboniferous Eurypterida: Trans. R. Soc. Edinb.: Earth Sci., v.63, p. 265-88.

Waterston, C.D., 1962, Pagea sturrocki gen. et sp. nov., a new eurypterid from the Old Red Sandstone of Scotland: Palaeontology, v. 5, p. 137-148.

Waterston, C.D., 1968, Further observations on the Scottish Carboniferous eurypterids: Trans. $R$. Soc. Edinb., v.68, p. 1-20.

Waterston, C.D., 1979, Problems of functional morphology and classification in stylonuroid eurypterids (Chelicerata, Merostomata), with observations on the Scottish Silurian Stylonuroidea: Transactions of the Royal Society of Edinburgh, v. 70, p. 251-322.

Waterston, C.D., Oelofsen, B.W., and Oosthuizen, R.D.F., 1985, Cyrtoctens wittebergensis sp. nov. (Chelicerata: Eurypterida), a large sweep-feeder from the Carboniferous of South Africa: Trans. R. Soc. Edinb.: Earth Sci., v. 76, p. 339-358, doi:10.1017/S0263593300010555.

Whyte, M.A., 2005, A gigantic fossil arthropod trackway: Nature, v.438, p.576, doi:10.1038/438576a.

Woodward, H., 1868, On some new species of Crustacea from the Upper Silurian rocks of Lanarkshire \&c.; and further observations on the structure of Pterygotus: $Q$ J Geol Soci., v. 24, p. 289-296, doi:10.1144/GSL.JGS.1868.024.01-02.36.

Woodward, H., 1872, A Monograph of the British Fossil Crustacea belonging to the Order Merostomata: Palaeontogr. Soc., v. 3, p. 71-120. 


\section{FIGURES AND TABLES}

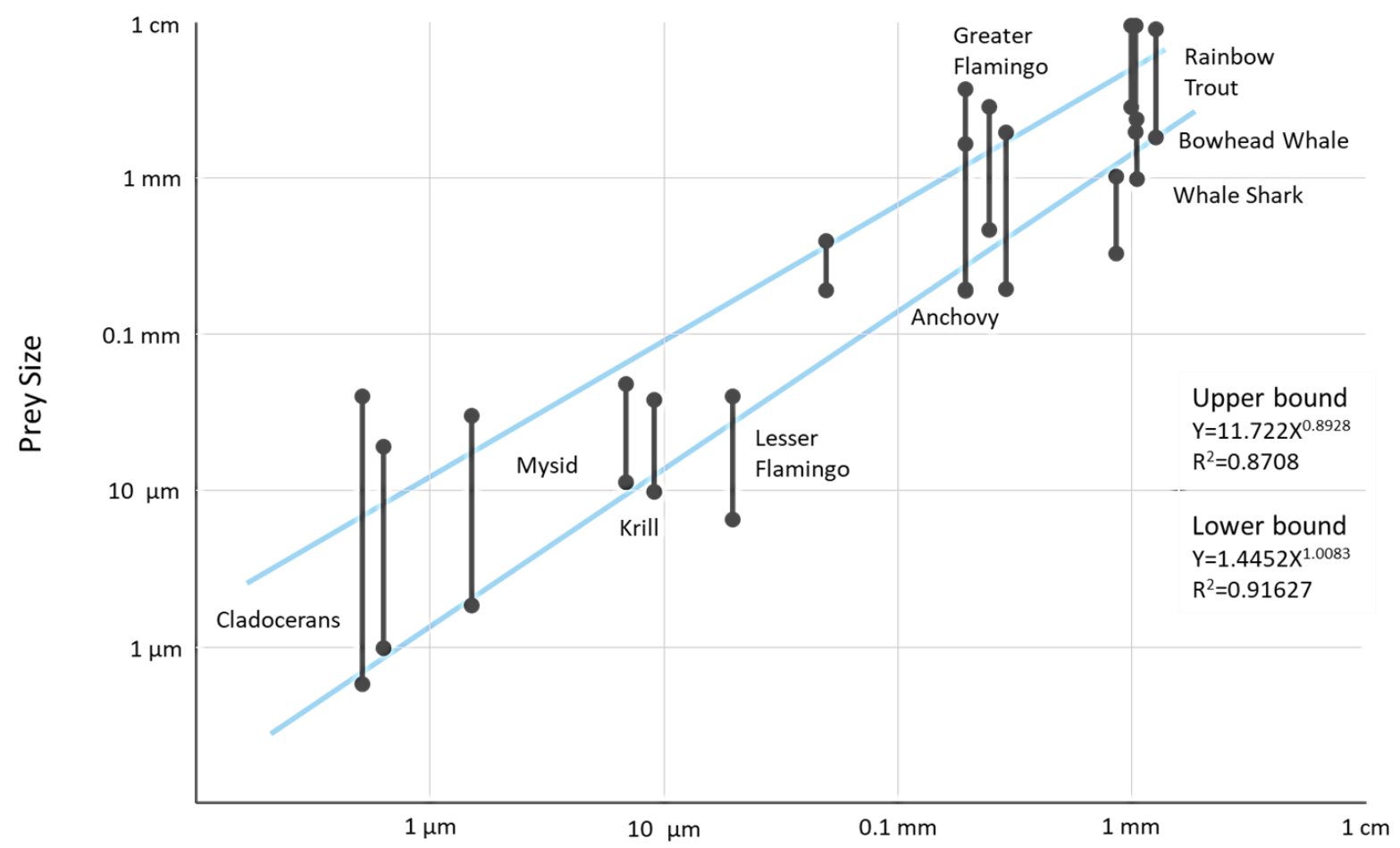

Filter Mesh Spacing

Figure 1. Relationship between the average filter mesh size and prey widths for a diverse group of extant suspension feeders (data from Vinther et al., 2014).
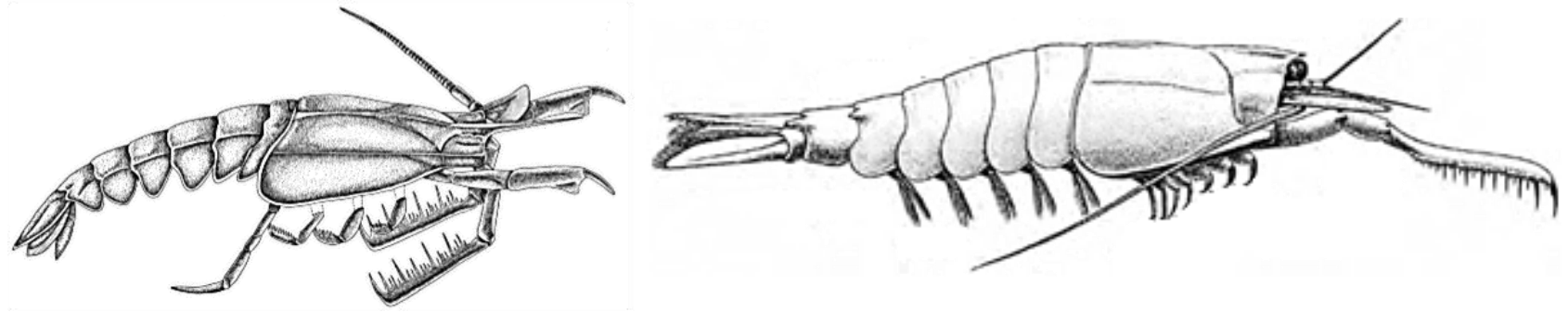

$1 \mathrm{~cm}$

Figure 2. (Left) Reconstructions of the sweep-feeding decapod Palaeopaleomon newberryi (from Jones et al., 2018).

Figure 3. (Right) Reconstruction of the predatory pelagic decapod Angustidontus seriatus (from Gueriau et al., 2014). 

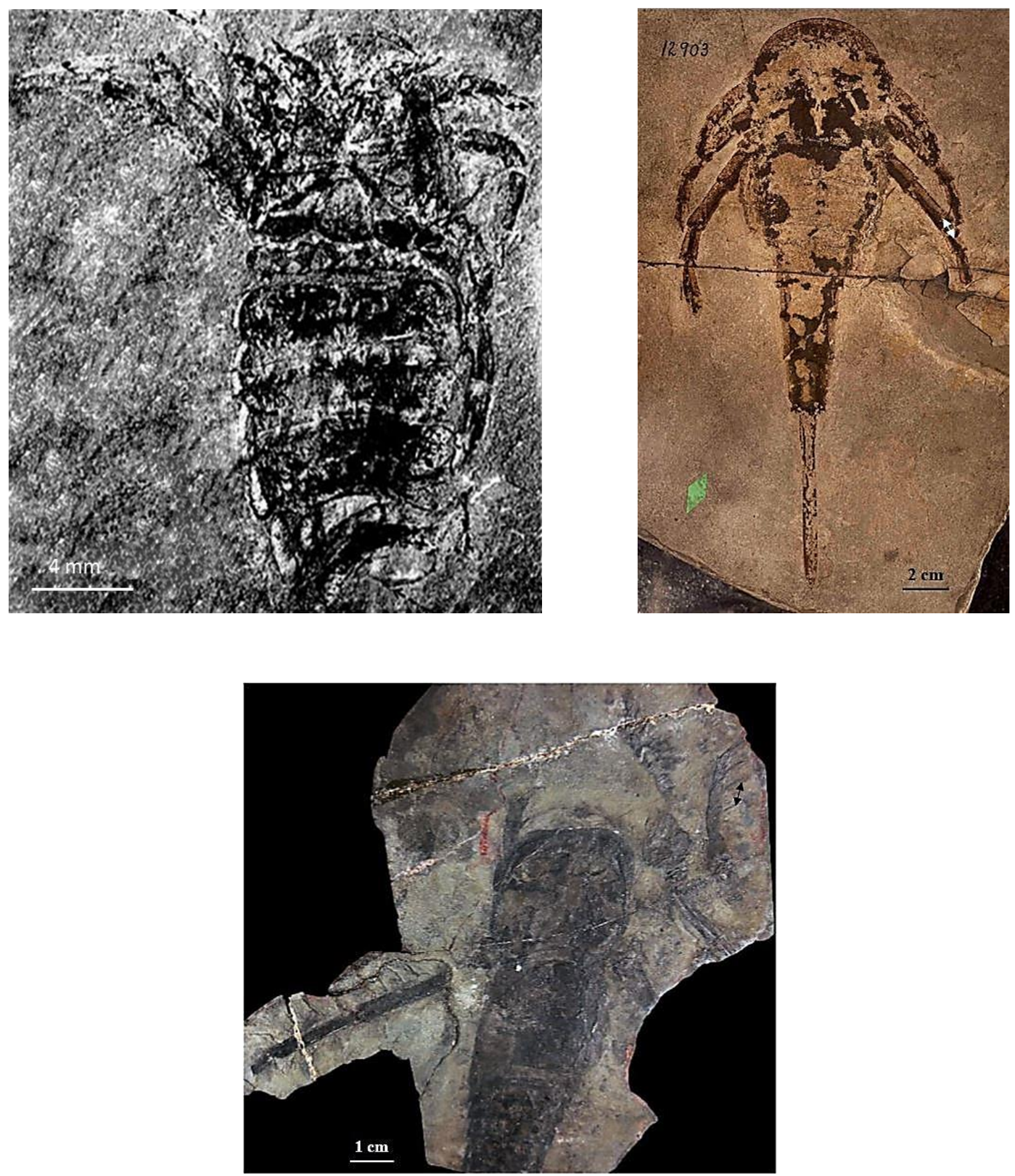

Figure 4. (Left) The bottom scavenging Rhenopterus diensti (from Størmer, 1934).

Figure 5. (Right) UC 12903. The bottom scavenging Kokomopterus longicaudatus.

Figure 6. (Bottom) BGS GSE 87357. The bottom scavenging parastylonurid Stylonurella spinipes.

* Arrows indicate example points of measurement. 

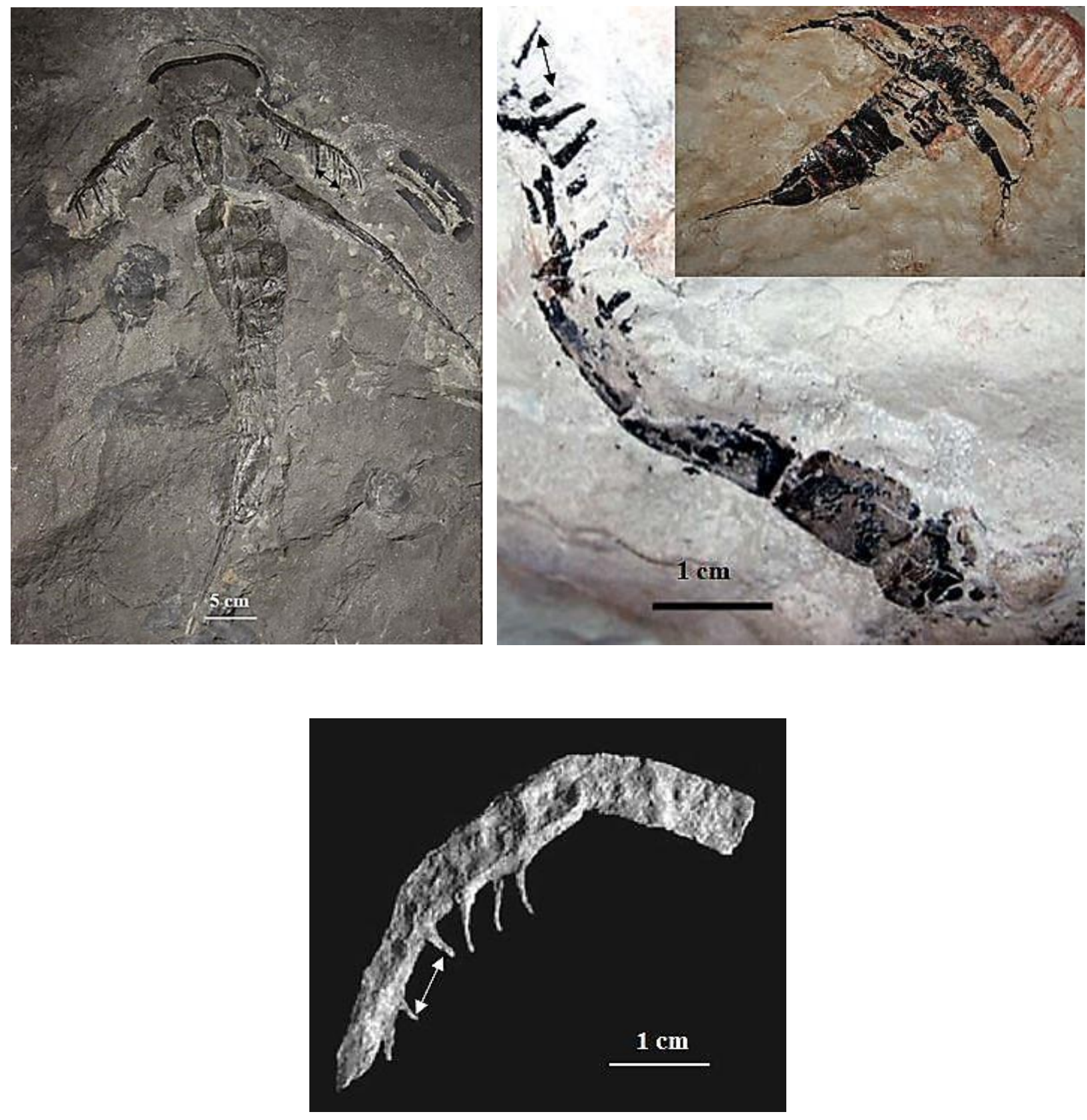

Figure 7. (Left) NMS RSM 1956.14.11. The stylonurid Pagea sturrocki, a likely trap feeder. Figure 8. (Right) A disarticulated spiniferous appendage (BKM 942) of the sweep-feeding stylonurid Soligorskopterus tchepeliensis (BKM 1052, inset) (from Plax et al., 2018). Figure 9. (Bottom) BGS GSM 84701. A spiniferous anterior appendage of the mycteropoid Drepanopterus abonensis (from Lamsdell et al., 2009).

* Arrows indicate example points of measurement. 


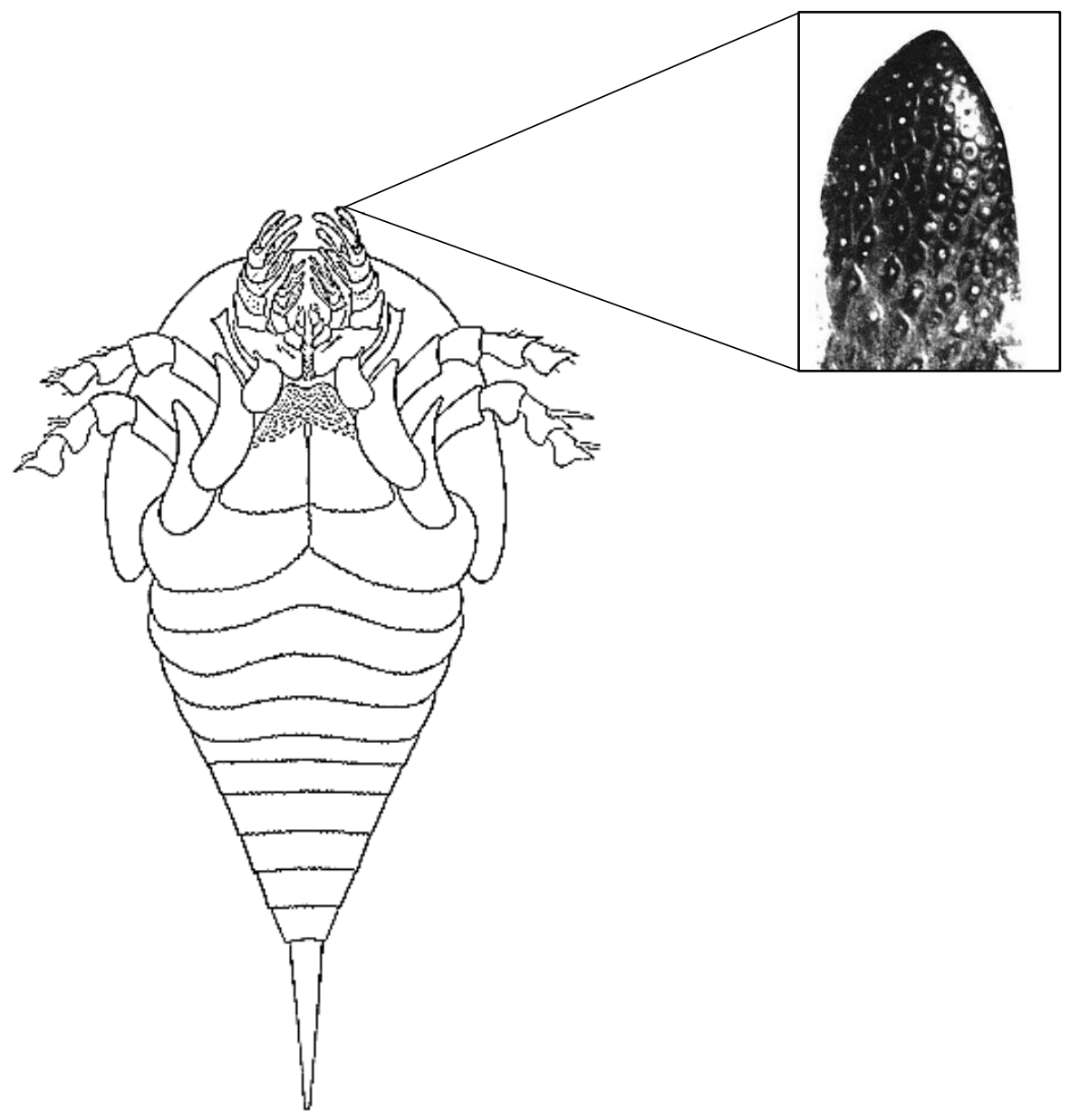

Figure 10. A ventral reconstruction of the sweep-feeding mycteropoid eurypterid Hibbertopterus scouleri and the distal portion of a moveable blade from an anterior appendage (G 55/76) showing the folliculated cuticular thickenings which likely bore sensory setae (from Waterston, 1957). 

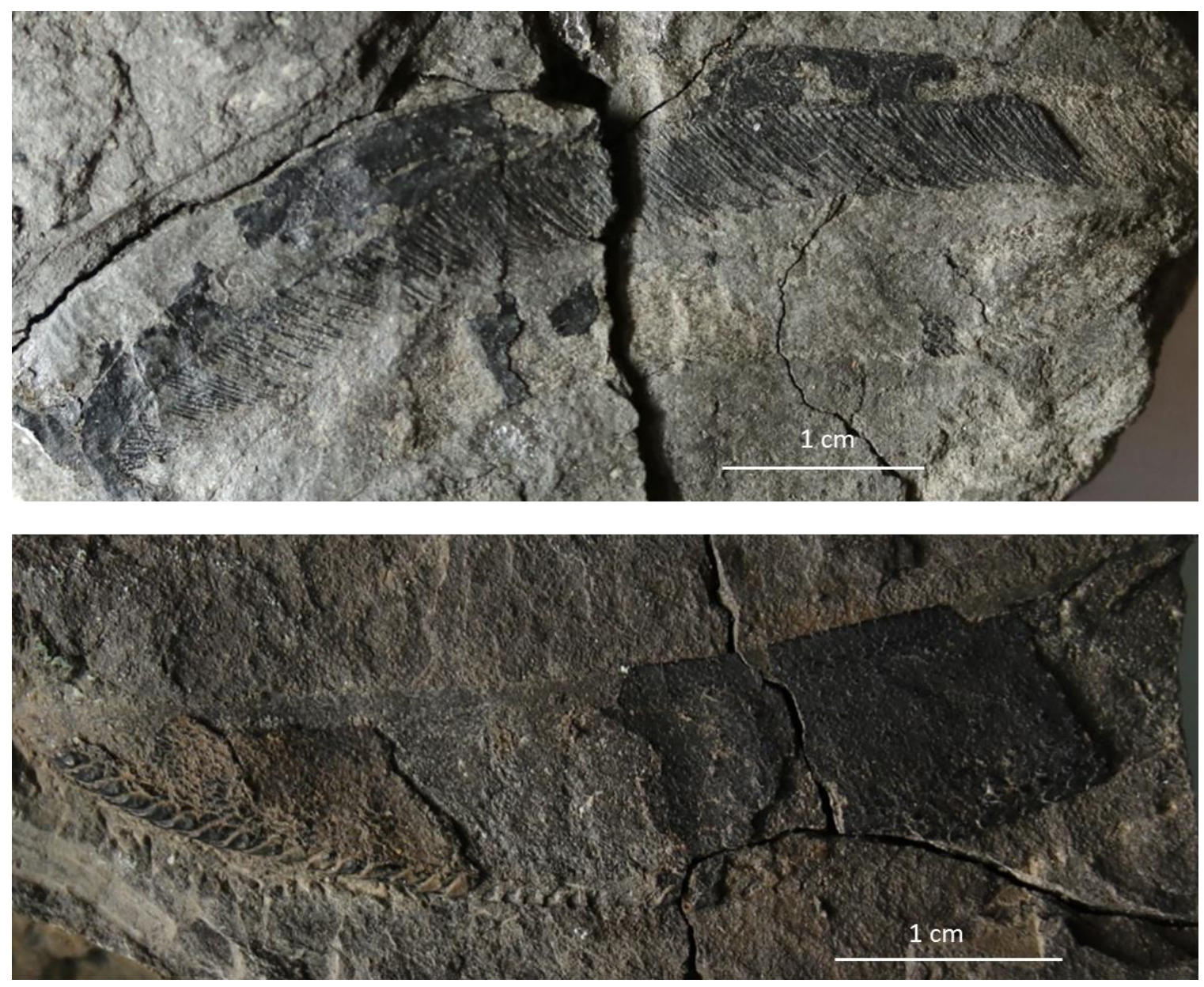

Figure 11. Disarticulated sweep-feeding armature of the mycteropoid Cyrtoctenus peachi. (Top) BGS GSE 2127. A comb-rachis bearing two rows of filaments protruding from the anterior margin. (Bottom) BGS GSE 9682. A moveable finger with fulcra along the posterior boarder.

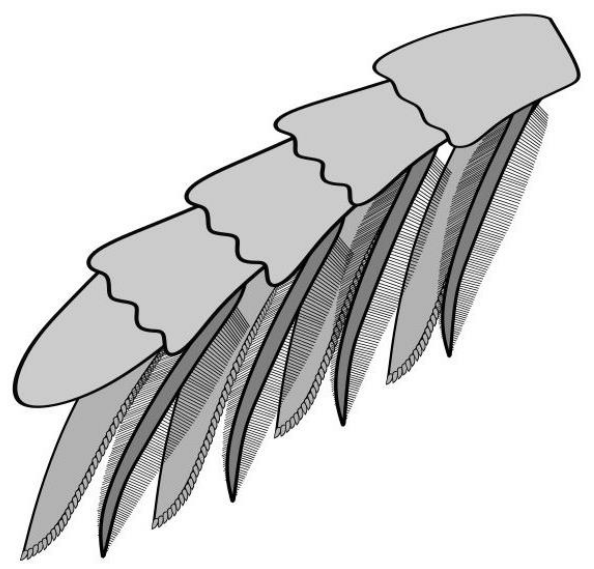

Figure 12. Reconstruction of the distal portion of a left anterior appendage of Cyrtoctenus viewed from the posterior. The two rows of filaments of each comb are directed anteriorly but splay outwards due to the opposing current which is generated as the appendages are drawn towards the ventral body wall. 


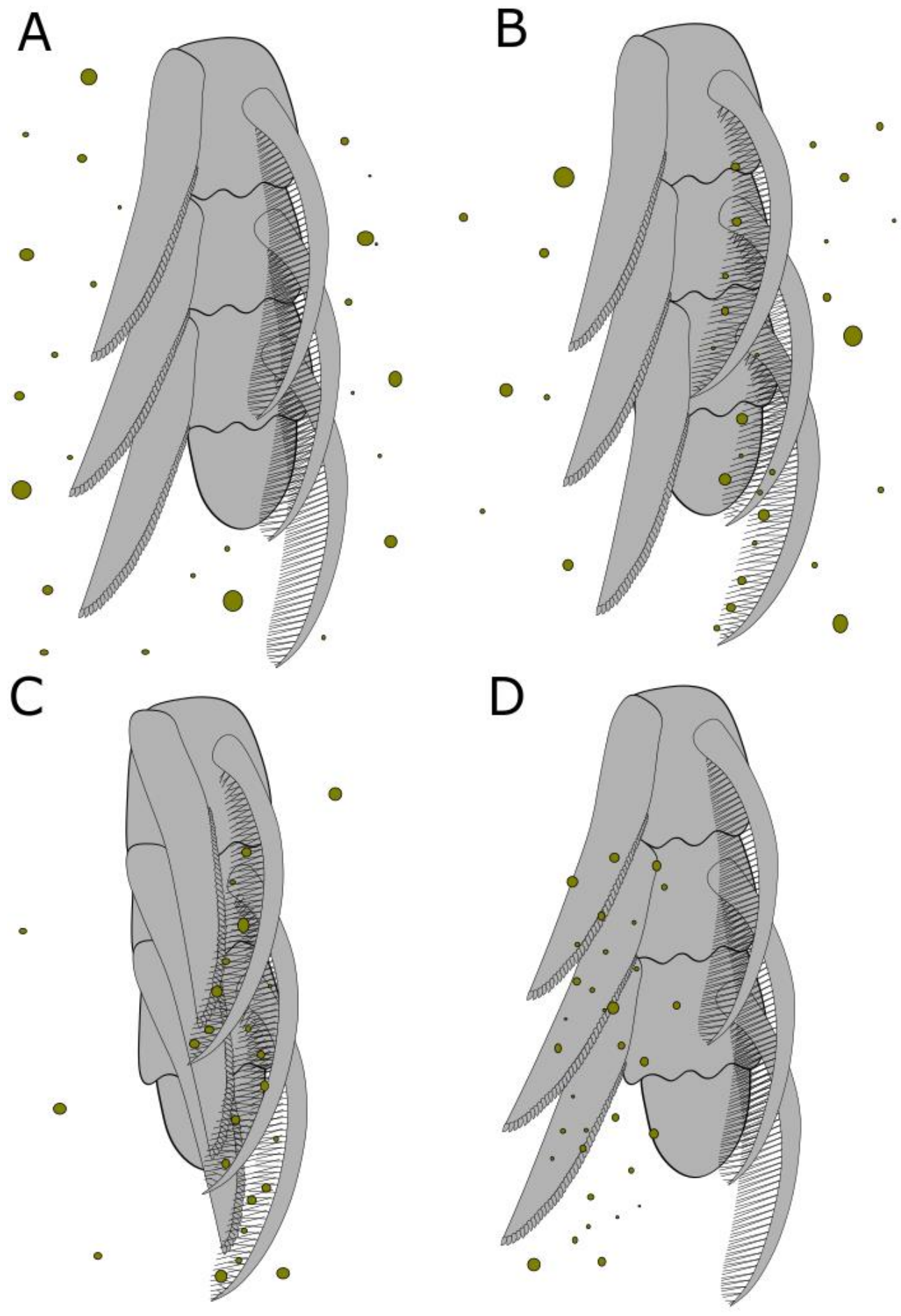

Figure 13. Possible function of Cyrtoctenus appendage armature in ventral view. The rows of filaments of the posterior comb would initially be closed (A) until the appendages were drawn towards the ventral body wall at which point the filaments would spread outwards and filter suspended particles (B). Upon initiating the backstroke, the anterior finger would insert between the closing rows of filaments (C) and slide outwards, scraping the filaments clean and ejecting particles into the oral region (D). 


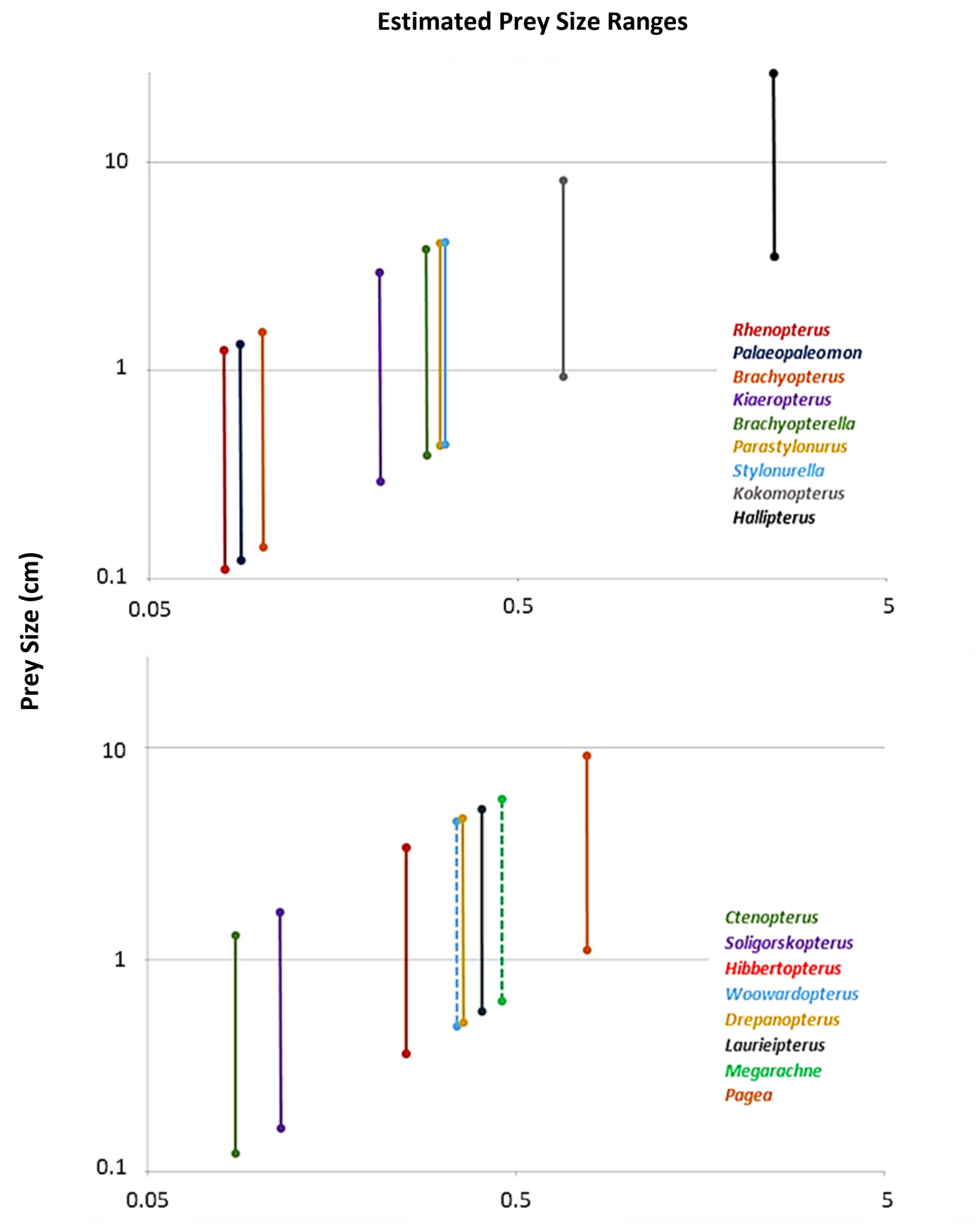

Armature Spacing $(\mathrm{cm})$

Figure 14. (Top) Estimated prey size ranges for rhenopteroid, kokomopteroid, and parastylonurid eurypterids and Palaeopaleomon based upon inter-armature spacing. Figure 15. (Bottom) Estimated prey size ranges of stylonurid and mycteropoid eurypterids. Dashed lines indicate measurements acquired from reconstructions. 


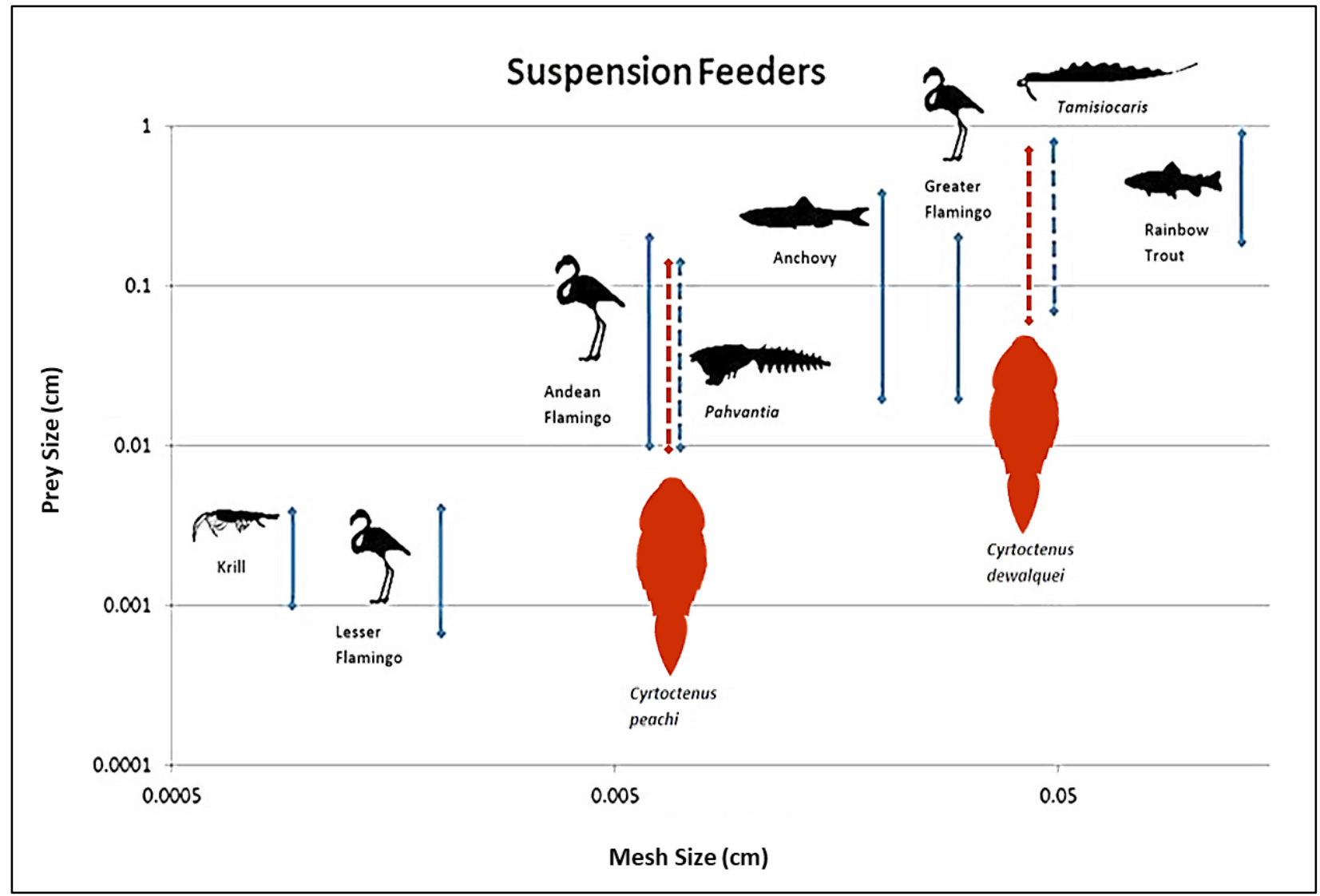

Figure 16. Prey size ranges of a diverse group of modern and fossil suspension feeders. Dashed lines indicate prey size ranges which were estimated from average filter mesh size using the methods of Vinther, et al. (2014). 

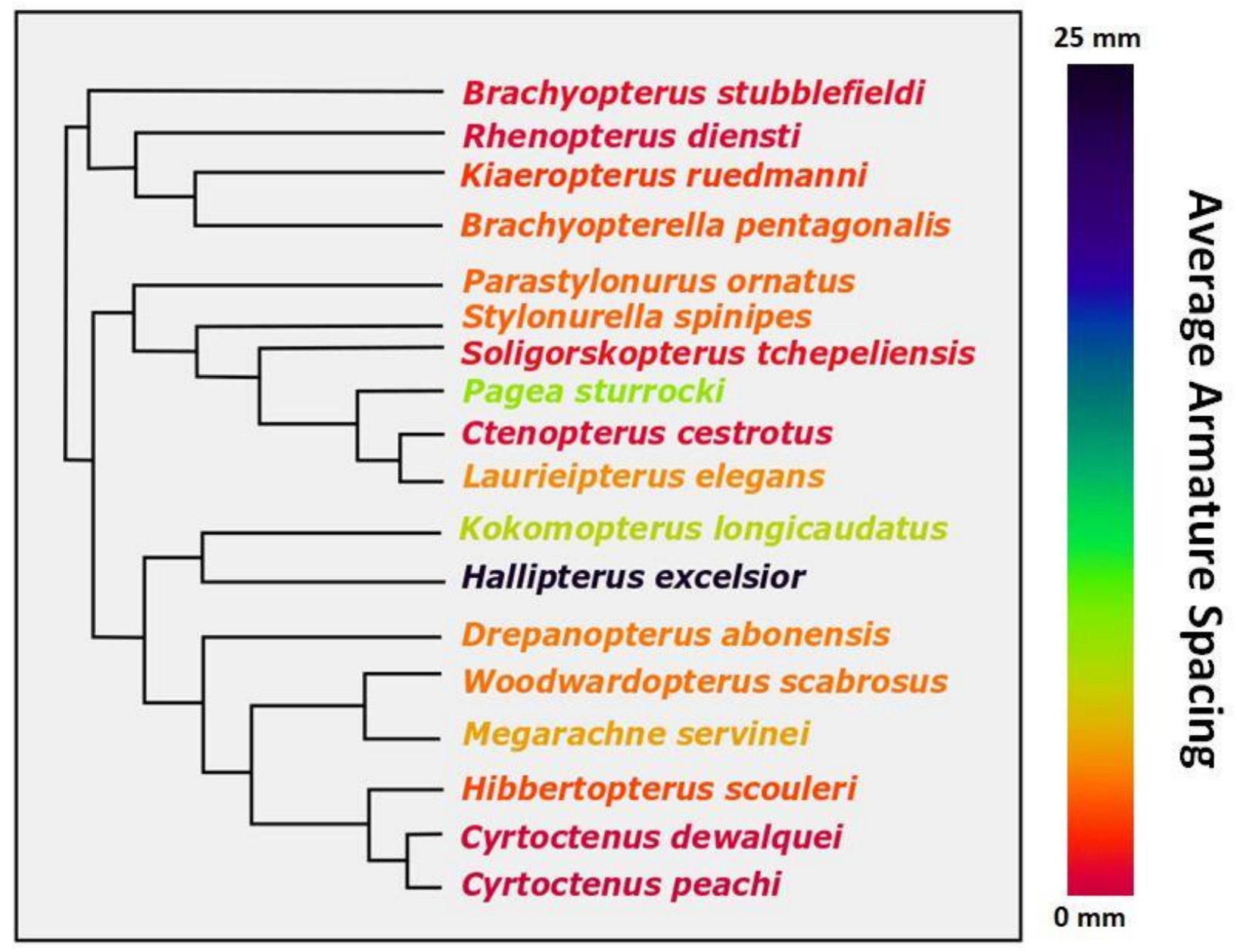

Figure 17. Cladogram of the stylonurine eurypterids included in this study. Colors correspond to the average inter-armature spacing of each species. 

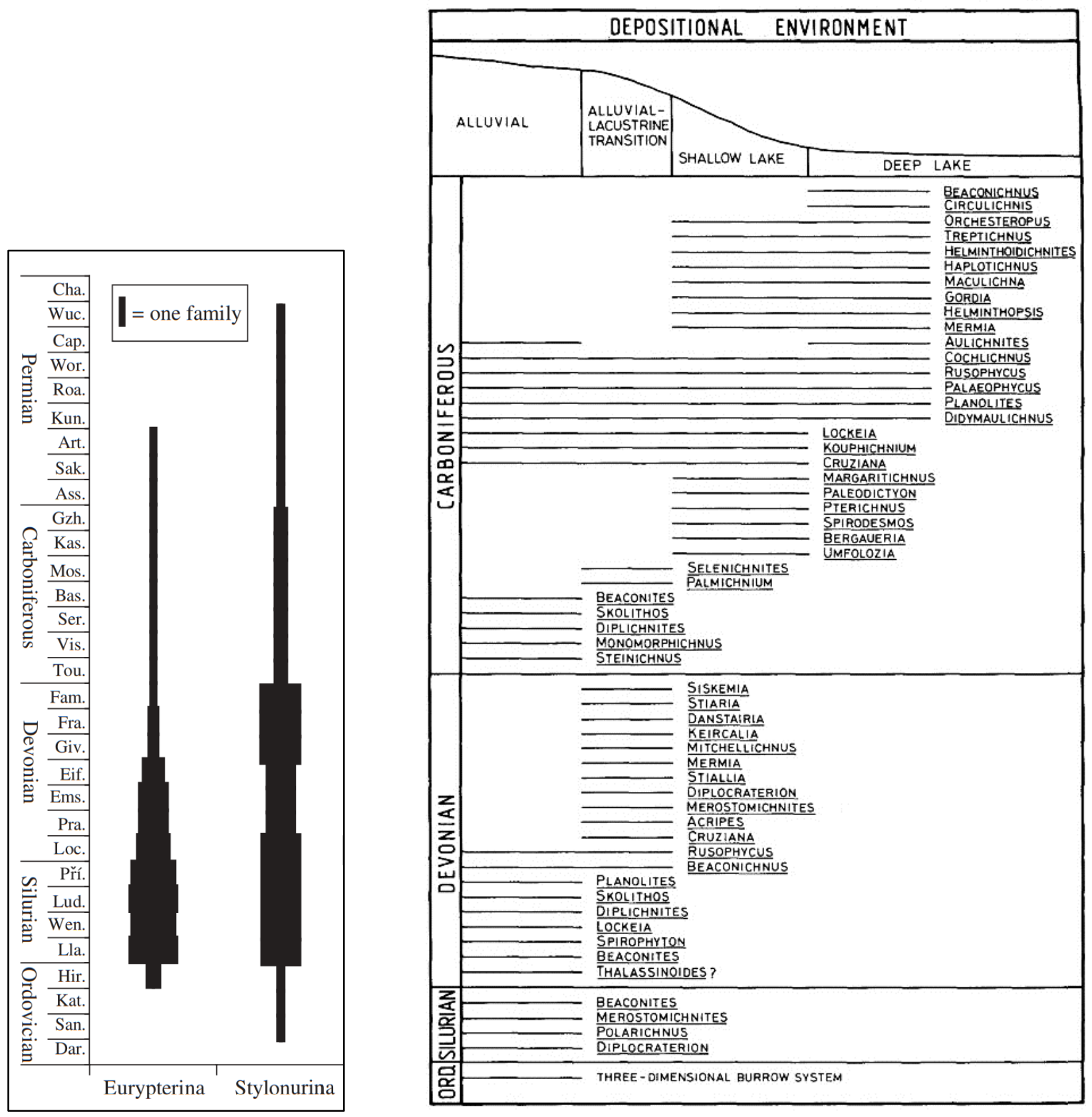

Figure 18. (Left) Diversity of eurypterine and stylonurine eurypterids throughout the Paleozoic (from Lamsdell and Braddy, 2010).

Figure 19. (Right) Plot of ichnogenera occurrences in alluvial to deep lake environments from the Ordovician through the Carboniferous (from Buatois and Mángano, 1993). 

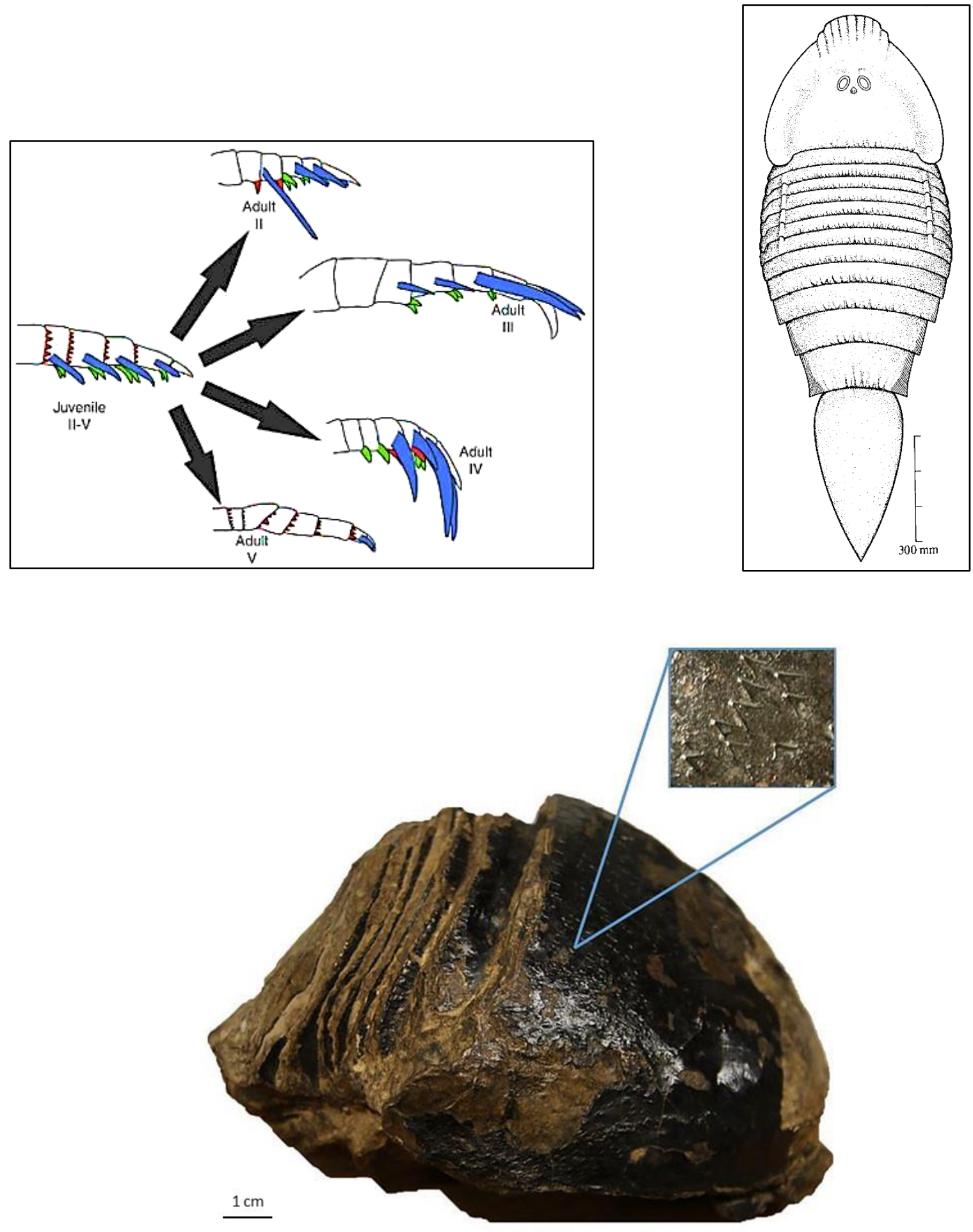

Figure 20. (Left) Ontogenetic changes in the prosomal appendages of Pentecopterus decorahensis. Appendage armature includes: denticulations (red), fixed lateral spines (blue), and moveable ventral spines (green) (from Lamsdell et al., 2015).

Figure 21. (Right) Reconstruction of Cyrtoctenus wittebergensis (from Waterston et al., 1985). Figure 22. (Bottom) NMS G 1955.15. Lateral view of the prosoma and anterior tergites of Hibbertopterus scouleri and an enlarged view of the mucrones ornamenting the carapace. 

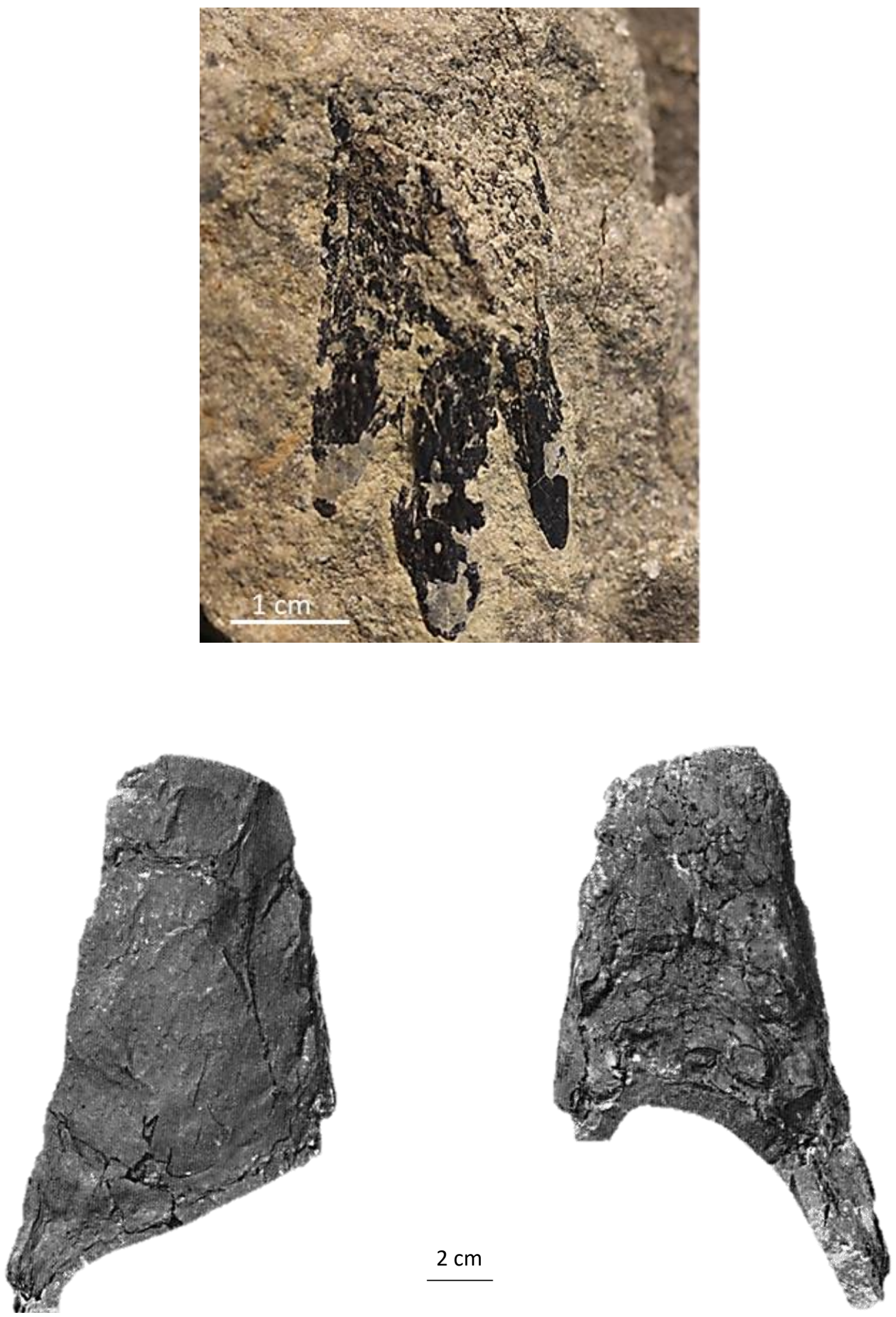

Figure 23. (Top) NMS G 1987.7.10. The tibia of appendage IV of Hibbertopterus scouleri bearing densely spaced linguiform ornamentation.

Figure 24. (Bottom) BGS GSE 12277. Dorsal (left) and ventral (right) view of a prosomal appendage segment belonging to Hibbertopterus (from Waterson, 1968). 

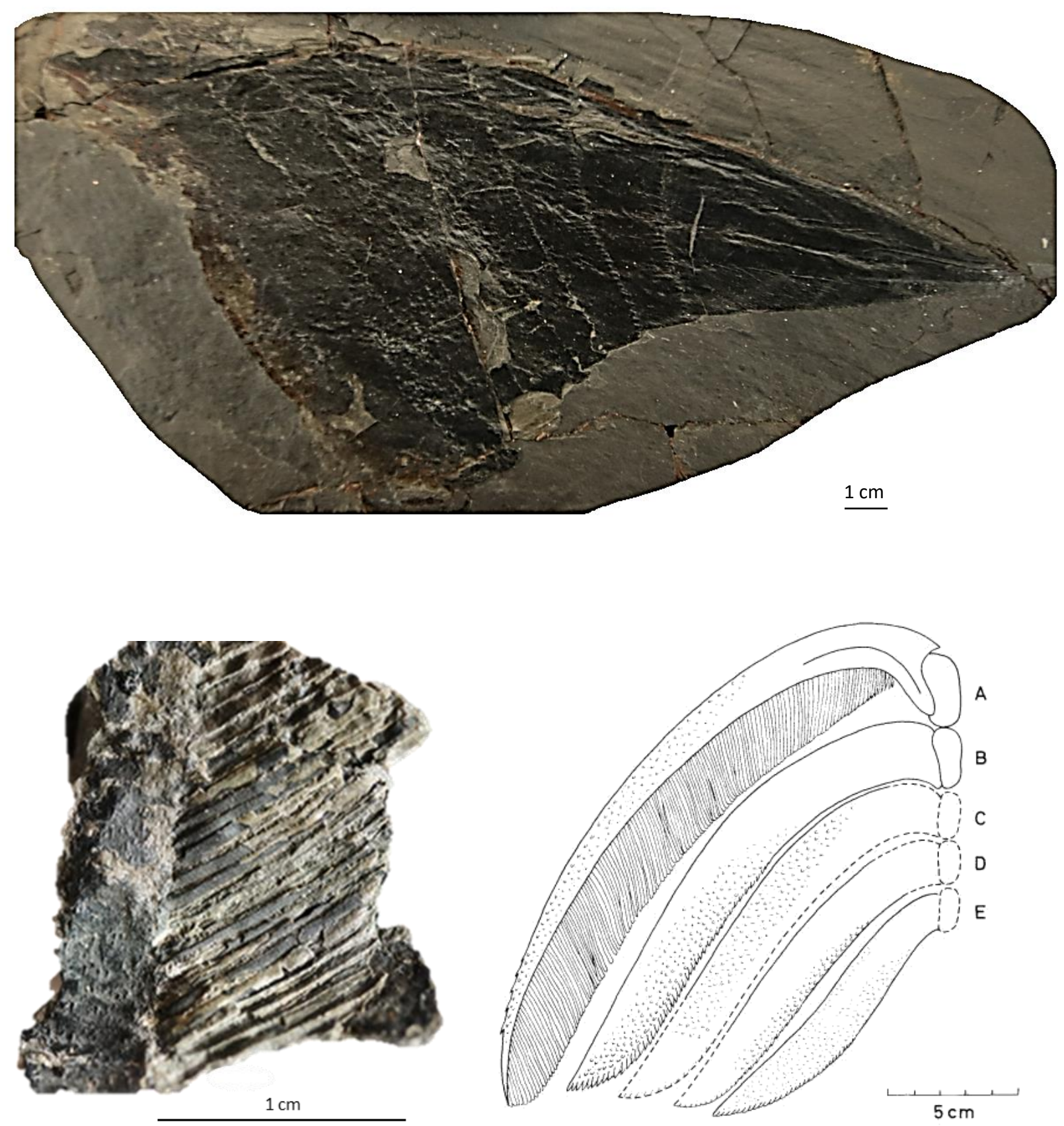

Figure 25. (Top) NMS 1992.14.6. The ventral portion of the metasoma of Hibbertopterus scouleri.

Figure 26. (Left) BGS GSE 2184. Cyrtoctenus peachi comb fragment with elongate scale tubercles ornamenting the rachis.

Figure 27. (Right) Cyrtoctenus armature types (from Størmer and Waterson, 1968). 

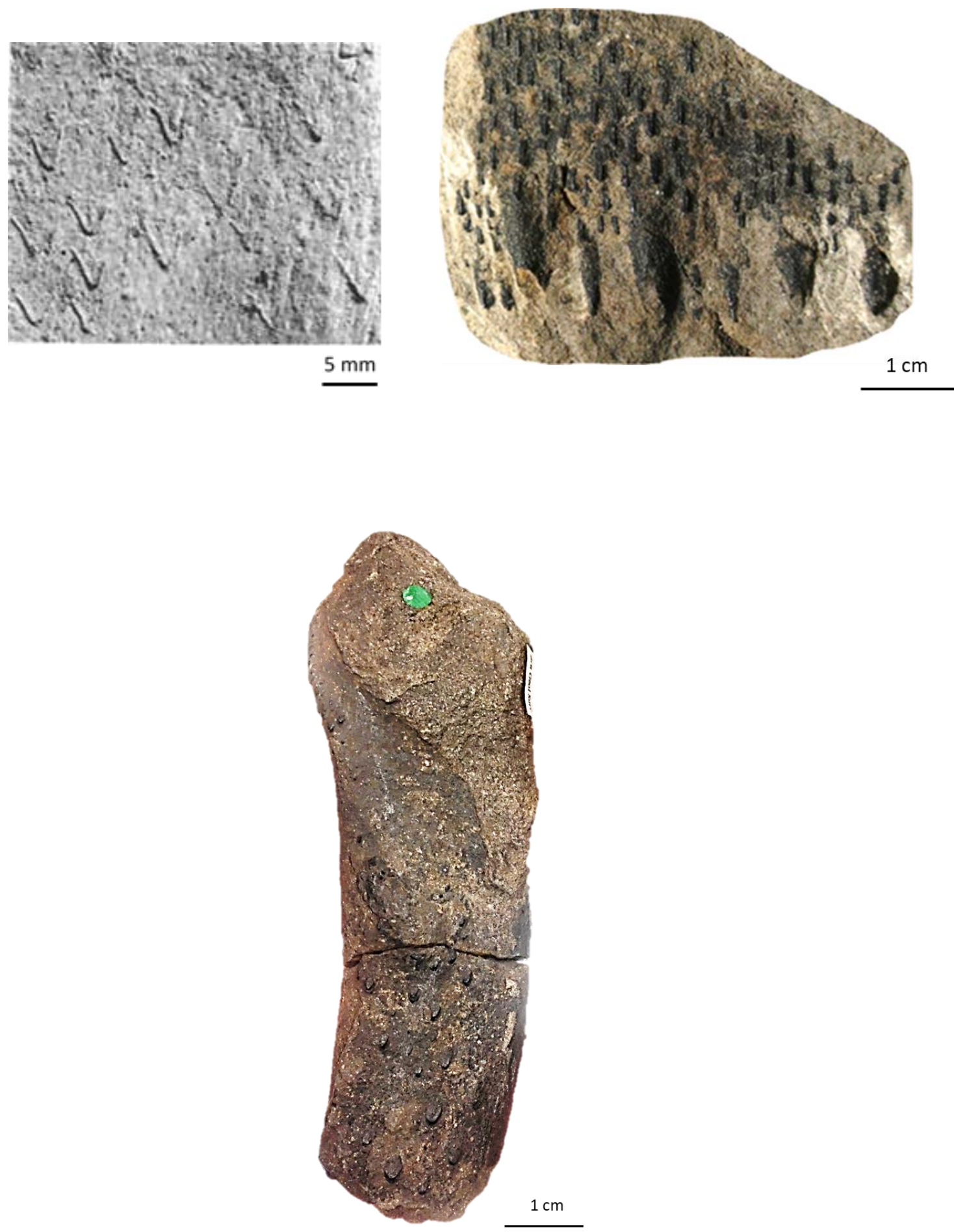

Figure 28. (Left) Mucrones on the carapace of $C$. wittebergensis (from Waterston et al., 1985). Figure 29. (Right) BGS GSE 2130. Anterior concave mucrones and large posterior spines ornamenting a tergite fragment of Dunsopterus stevensoni. Figure 30. (Bottom) BGS GSE 9707. A Dunsopterus podomere bearing widely spaced linguiform scales. 


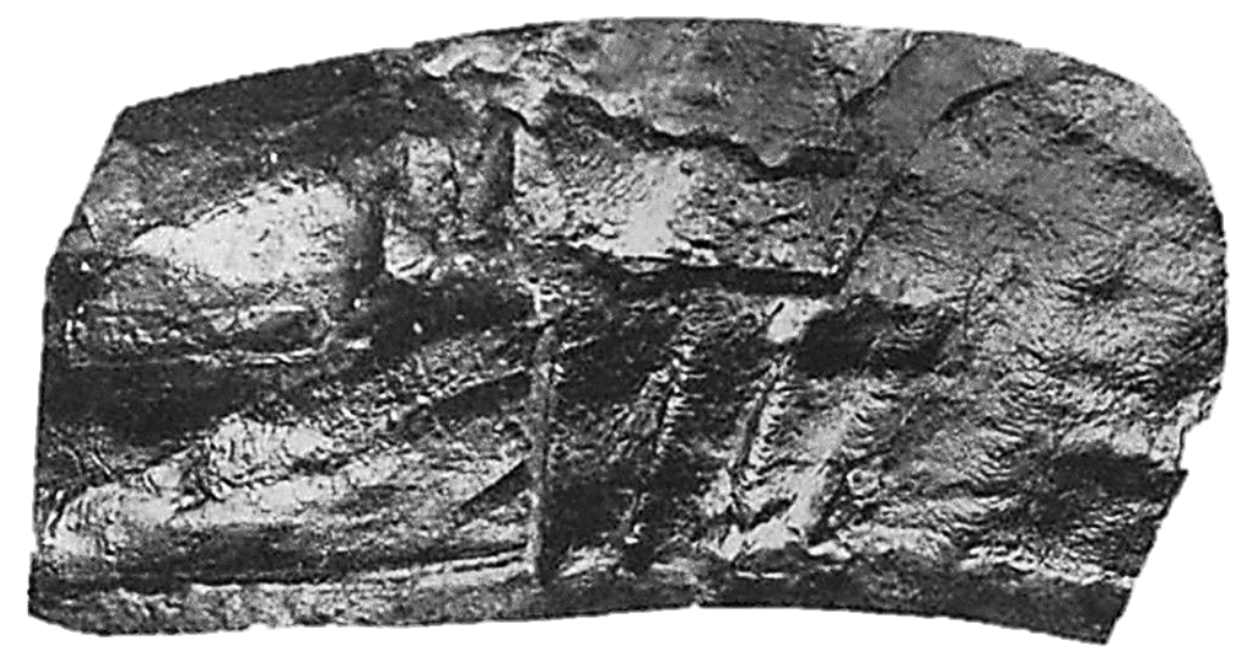

$1 \mathrm{~cm}$
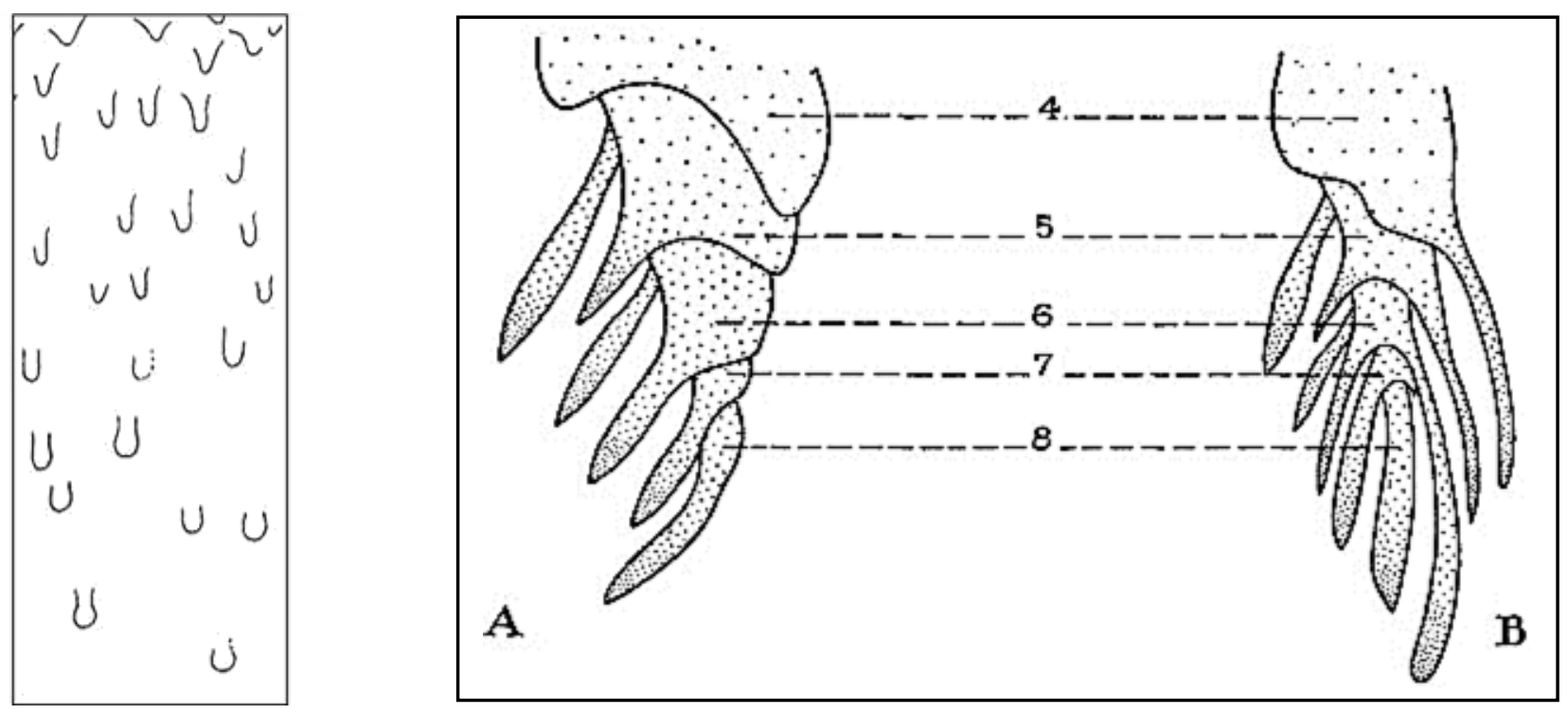

Figure 31. (Top) NMS RSM 1957.1.4992. Longitudinal dorsal tergite ridges consisting of semilunular scales in Vernonopterus minutisculptus (from Waterston, 1968).

Figure 32. (Left) Transition of mucrones into inverted "keyhole" shaped scales on tergite fragments possibly belonging to Cyrtoctenus dewalquei (modified from Størmer and Waterston, 1968).

Figure 33. (Right) Reconstruction of the distal portion of an anterior appendage of Hibbertopterus scouleri showing the configuration of moveable blades in lateral (A) and posterior (B) view. Podomeres are labeled numerically (from Waterston, 1957). 

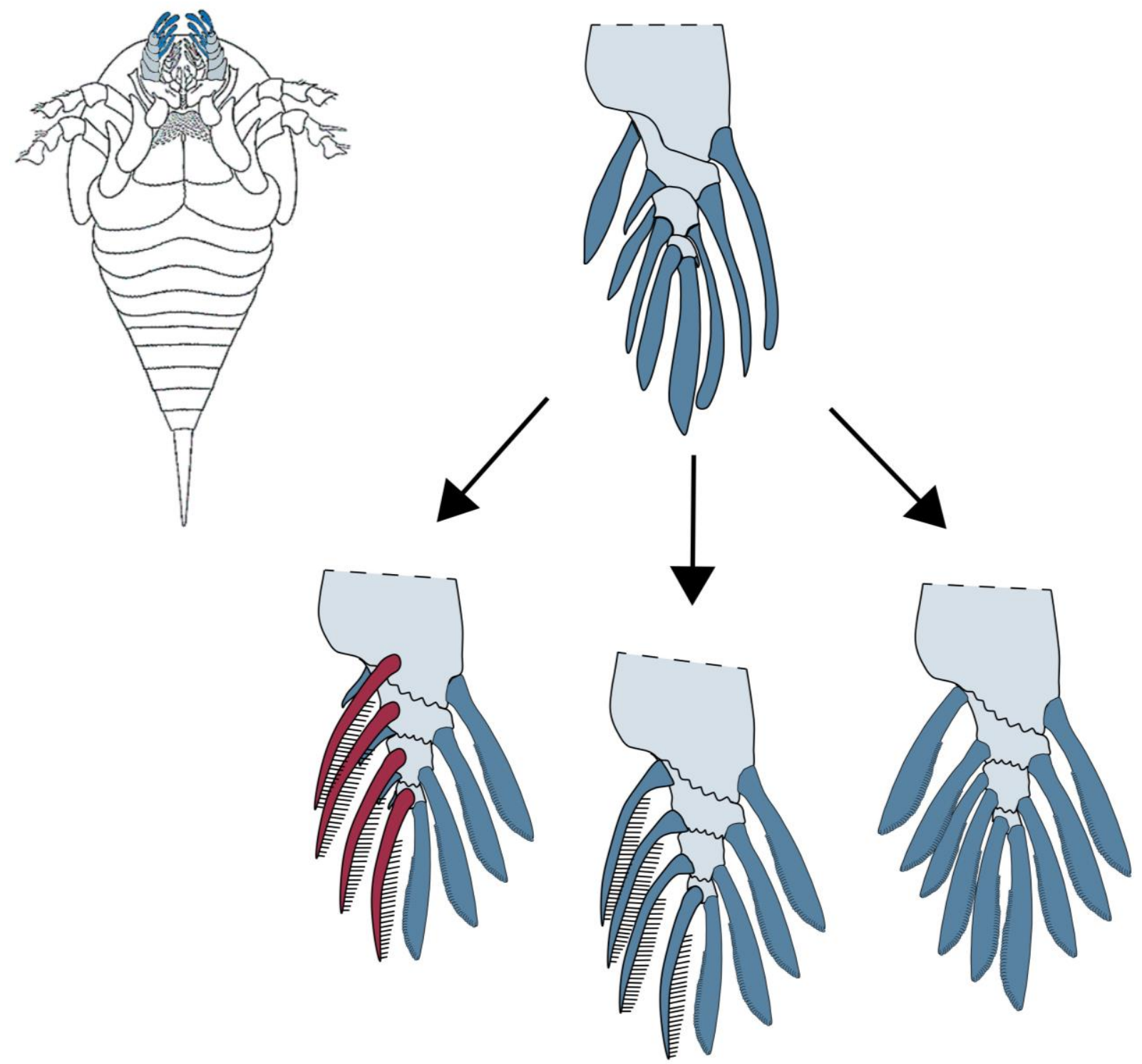

Figure 34. Possible scenarios for the ontogenetic changes in the anterior appendages of Hibbertopterus. The blades of the juvenile appendages (top) likely developed into Cyrtoctenustype moveable fingers with fulcra. Some of these blades may have been lost or reduced in adults to make room for the development of combs (left), or the combs may be derived from blades which developed filaments (middle). Finally, combs may have been absent on the anterior most appendages (right). In this scenario, the fingers may have been used to disturb bottom sediment, allowing combs on posterior appendages to filter organic particles from the resulting cloud of suspended sediment. 


\begin{tabular}{|l|l|}
\hline Species & Specimens \\
\hline Rhenopteroidea & \\
\hline Brachyopterus stubblefieldi & BGS D3124 \\
\hline Rhenopterus diensti & Pl. 10, fig.4 in Størmer (1936) \\
\hline Brachyopterella pentagonalis & H 2050 \\
\hline Kiaeropterus reudmanni & H 1711 \\
\hline Kokomopteroidea & \\
\hline Kokomopterus longicaudatus & UC 12903 \\
\hline Hallipterus excelsior & Text-fig. 1B in Clark and Reudmann (1912) \\
\hline Parastylonuridae & \\
\hline Parastylonurus ornatus & NMS G 1897.32.69a \\
\hline Stylonurella spinipes & BGS GSE 87357, NMS G 1891.92.33 \\
\hline Stylonuridae & \\
\hline Ctenopterus cestrotus & Pl. 49, fig. 4 in Clark and Reudmann (1912) \\
\hline Lauriepterus elegans & NMS G1897.32.66, NMS G 1897.32.67 \\
\hline Pagea sturrocki & NMS RSM 1956.14.11 \\
\hline Soligorskopterus tchepeliensis & BKM 105, BKM 942 \\
\hline Mycteropoidea & \\
\hline Drepanopterus abonensis & BGS GSM 84701, BRSUG 28857 \\
\hline Megarachne servinei & Text-figs. A-D in Selden et al. (2005) \\
\hline Woodwardopterus scabrosus & Text-figs. E-F in Selden et al. (2005) \\
\hline Hibbertopterus scouleri & NMS G 1987.7.10, G 55/76 \\
\hline Cyrtoctenus peachi & NMS G 1984.69.1, BGS GSE 2127 \\
\hline Cyrtoctenus sp. & NMS G 1987.7.24 \\
\hline Cyrtoctenus dewalquei & RE 14786A \\
\hline &
\end{tabular}

Table 1. List of eurypterid specimens in which inter-armature spacing was measured. 